\title{
El gerente municipal. Una aproximación al cambio en la acción de gobierno y la gestión pública
}

\author{
Joan Pere López Pulido \\ Profesor colaborador en Derecho Administrativo II de la Facultad de \\ Derecho de ESADE-Universidad Ramón Llull \\ Profesor colaborador en Teoría de la Organización de la Escuela de \\ Administración Pública de Cataluña
}

\begin{abstract}
Sumario: I. INTRODUCCIÓN. La modernización en la Administración Pública. II. LA FUNCIÓN GERENCIAL. 2.1. La gestión pública. Desde los modelos. Desde las técnicas de gestión. 2.2. El perfil del directivo. III. EL GERENTE MUNICIPAL. 3.1. Introducción. 3.2. El gerente local a nivel comparado. 3.3. Modelos organizativos. Modelo clásico con técnicos-administradores. Modelo de dirección política. Modelo gerencial. Dos experiencias singulares. En Barcelona. En Esplugues de Llobregat. 3.4. El marco jurídico en Cataluña. La legislación vigente. Desde la organización ejecutiva del Ayuntamiento. Desde la organización ejecutiva de los entes instrumentales de gestión directa. 3.5. Mucho más que una figura o un modelo. El cubo de Rubik, paradigma de la gestión local. REFERENCIAS SOBRE ORGANIZACIÓN. BIBLIOGRAFÍA CONSULTADA.
\end{abstract}

\section{INTRODUCCIÓN}

«Por autonomía local se entiende el derecho y la capacidad efectiva de las Corporaciones locales de ordenar y gestionar una parte importante de los asuntos públicos, en el marco de la ley, bajo su propia responsabilidad y en beneficio de sus habitantes».

(Carta Europea de Autonomía local, art. 3.1).

«Las Corporaciones locales deben poder definir por sí mismas las estructuras administrativas internas con las que pretenden dotarse, con objeto de adaptarlas a sus necesidades específicas y a fin de permitir una gestión eficaz».

(Carta Europea de Autonomía local, art. 6.1).

\section{¿Qué?}

El presente trabajo pretende ser una reflexión sobre la figura del gerente municipal, pretexto para realizar una aproximación a la acción de gobierno y la gestión pública en los municipios catalanes. 
En el ámbito de la Administración Pública, los Ayuntamientos son las organizaciones prestacionales, de base territorial, más próximas a los ciudadanos $\mathrm{y}$, al mismo tiempo, se encuentran en situación privilegiada para detectar y actuar sobre sus necesidades, e incluso preverlas o condicionarlas mediante la prospectiva, que en muchos casos se articula a través de los Planes estratégicos.

A lo largo de la presente monografía se analiza la evolución del concepto de eficacia hacia el de eficiencia en las Administraciones públicas, mediante el reclamo, generalizado internacionalmente, de modernización y reinvención del gobierno. Gobierno y administración que se estudian como conceptos complementarios, pero diferenciados en cuanto a su alcance material, para delimitar el entorno de la gestión pública desde sus diferentes modelos y técnicas, lo que permitirá definir la figura del gerente municipal, en su vertiente organizativa, gerencial y jurídica. Y, con él, la acción de gobierno, de dirección política, dentro de la cual se incardina como catalizador intraorganizativo de las diferentes políticas públicas. Sin olvidar, que son los miembros electos de las Corporaciones locales, los que, utilizando como instrumentos los órganos administrativos correspondientes, detentan el mandato representativo de los ciudadanos para gestionar la organización municipal, según los programas políticos de partidos y agrupaciones electorales que acaben conformando finalmente el gobierno municipal y, que se concretarán en políticas públicas determinadas.

En la base del edificio constitucional del Estado y siendo uno de sus pilares vertebradores, queda garantizada la autonomía de los municipios, correspondiendo al Ayuntamiento su gobierno y administración. Garantía institucional revestida de potestades que la hacen efectiva, entre ellas las de autoorganización y reglamentaria (capacidad normativa), que permiten, hasta cierto punto, rediseñar la organización del Ayuntamiento, para alcanzar los objetivos, legitimados por el poder electoral, de quienes asumen la acción de gobierno, de forma directa, o indirecta mediante acuerdos programáticos entre diferentes candidaturas.

\section{¿Cómo?}

«Las cosas son como son hasta que dejan de serlo».

\section{A. MACHADO}

Son pocos los Ayuntamientos que no han invertido esfuerzos e importantes y costosos recursos en adaptar sus estructuras organizativas a constantes reformas, pero sin cambiar la cultura de la organización, ni de sus gobernantes, lo que ha abocado en sentimiento de fracaso. Y, por otro lado, si bien la preocupación por la gestión acaba siendo un aspecto de trascendental importancia en las agendas públicas de los cargos electos (en las que priorizan su acción de 
EL GERENTE MUNICIPAL UNA APROXIMACIÓN AL CAMBIO ...

gobierno) una vez que detentan el poder, no se materializa en la posterior definición de políticas públicas (donde se defina el modelo de organización que más se adapte a las necesidades del municipio), ni se suele contener en los correspondientes programas electorales, no existiendo un debate a nivel político, ni una definición desde los partidos sobre los modelos de gestión en la Administración local.

Así, los dos municipios más importantes de Cataluña, por su población y dimensión de sus estructuras organizativas, gobernados mayoritariamente por la misma fuerza política, como son el caso de Barcelona y Hospitalet de Llobregat, si bien que en el primero con la concurrencia de otras dos, se asientan en modelos de gestión totalmente diferentes. El primero, organizado sobre la base de una estructura gerencial y, el segundo, sobre los modelos tradicionales burocráticos de gestión municipal.

En este estudio se reflexiona sobre la acción de gobierno desde la perspectiva de la gestión pública, a través del modelo gerencial, no como paradigma de la excelencia o la calidad, según los parámetros conceptuales que corresponderían a la teoría de la organización, sino como resultado de un mejor aprovechamiento de los recursos organizativos, en un entorno extraordinariamente complejo, como lo es el municipal, donde la interacción con los diferentes agentes externos e internos (como lo son dentro de la organización: los grupos políticos municipales, el alcalde, los concejales, los directivos, el secretario-interventor-tesorero - si lo hay-, el personal, los sindicatos; $y$, fuera de la organización: los partidos o agrupaciones electorales, las entidades, las asociaciones, los colectivos organizados de todo tipo - político, sindical, económico, profesional, social-, los ciudadanos), acaba condicionando, no tan sólo las agendas y políticas públicas, sino también, la propia gestión en sí.

Y la calidad de la gestión resultante se percibirá por su perfume (en alegoría a la excelente novela de Patrick Süskind). Perfume del cual será responsable, en gran medida, el gerente, que junto al alcalde y al gobierno municipal, tienen la obligación de extraer la mejor esencia de cada uno de los agentes que interactúan en la administración, para conseguir la fórmula magistral que permita alcanzar altos grados de satisfacción en la mayor parte de ellos, sino en la totalidad.

«El desarrollo de la receptividad de la Administración puede resultar costoso, debido al aumento de servicios que se prestan a los clientes y al funcionamiento menos económico de los servicios administrativos. No obstante, el resultado puede ser provechoso si las políticas son más eficaces, si con ello aumenta la equidad y el público está satisfecho del comportamiento de la Administración. 
El aumento de la receptividad de la Administración es un reto esencial lanzado a las democracias más industrializadas.

¿Está el servicio público al servicio del público? Si la idea de servicio es primordial, ¿por qué la organización y los procedimientos administrativos dificultan tanto su realización?»

Informe OCDE «La Administración al servicio del público» 1987.

\section{La modernización en la Administración pública...}

«Valores nuevos a implantar en la cultura administrativa:

* La eficacia y la eficiencia como valores que junto a la legalidad constituyan los pilares de la actuación de la Administración.

* La responsabilidad efectiva de la Administración ante los ciudadanos destinatarios de los servicios públicos, instrumentando para ello los mecanismos que faciliten la mutua relación, hagan más accesible a la Administración y promuevan la participación ciudadana en la gestión pública.

* La asunción por los órganos políticos de las decisiones estratégicas y la realización por la Administración de las funciones para su ejecución, con el fin de hacer efectivo el principio de responsabilidad en la gestión en un marco de objetivos claramente establecido.

* En lo organizativo, flexibilidad de las estructuras con objeto de que puedan adaptarse a los requerimientos de las tareas a desempeñar en cada caso, y autonomía mayor en su funcionamiento de acuerdo con el criterio anterior.

* Apertura constante de la Administración a las experiencias e innovaciones introducidas en el funcionamiento de otras organizaciones públicas o privadas, con una particular sensibilidad hacia la incorporación de nuevas técnicas de gestión.

* Consideración de los recursos humanos como el elemento fundamental con el que opera la Administración, prestándoles una atención especial a partir de dos criterios centrales: adecuación de los regímenes de personal a las características de las tareas que tienen que desarrollar, e incremento constante de su profesionalización.»

Reflexiones para la modernización de la Administración del Estado. Madrid 1990.

...se plantea sobre la base de mejora de su funcionamiento, a través de un énfasis especial en el enfoque de la Administración como un conjunto de organizaciones cuya misión básica es prestar servicios públicos, con el nivel de calidad que demanda la sociedad actual (con la consecuencia de la necesidad de prestar una atención especial a la dimensión de la eficacia en la gestión del interés público). No olvidando la valoración específica que debe tener la restricción que supone, en la actualidad y en el futuro, la escasez de recursos de la Administración (con la consecuencia de la priorización de la eficiencia, a tra- 
EL GERENTE MUNICIPAL. UNA APROXIMACIÓN AL CAMBIO ...

vés, justamente, de la modernización de la gestión pública). Por ello es necesaria una articulación abierta y flexible del sistema de gestión dada la complejidad de la organización administrativa!

«Debe considerarse que no hay nada más difícil de llevar a cabo, ni con más incertidumbre de éxito, ni más peligroso de manejar, que iniciar un nuevo orden de cosas. $Y a$ que el reformador tiene enemigos en todos aquellos que se benefician del viejo orden, y solamente defensores indiferentes en todos aquellos que se beneficiarian por el nuevo orden. Esta indiferencia proviene parcialmente del miedo a sus adversarios, que tienen las leyes a su favor, y parcialmente, de la incredulidad del hombre, que verdaderamente no cree en nada nuevo hasta que no lo haya experimentado realmente». (Maquiavelo en El Príncipe, citado por Les Metcalfe y Sue Richards).

Sue RichaRds ${ }^{2}$ nos diagrama de manera muy concisa, la evolución en el propio concepto de modernización, sobre la base de tres paradigmas, el de la Administración Pública, el de la Eficiencia y el del Cliente. En el paradigma de la Administración Pública los políticos y aquellos técnicos que trabajan cerca de ellos, se basan en el mandato electoral para tomar decisiones en nombre de la comunidad. Son los que han de fijar los grandes parámetros de los servicios públicos $y$, en la medida en que no definen específicamente los detalles de una política de servicio, los profesionales y las burocracias llenan ese vacío, patrimonializando como propio ese terreno. Los productores de los servicios públicos suelen ser profesionales que autorregulan su función, controlando el acceso a los mismos y definiendo sus normas, teniendo una gran capacidad de influencia en las correspondientes políticas públicas. Y en este paradigma, el administrador aparece como integrador entre el entorno político y el de productores, no implicándose en los objetivos.

\section{FIGURA 1. El paradigma de la Administración pública}

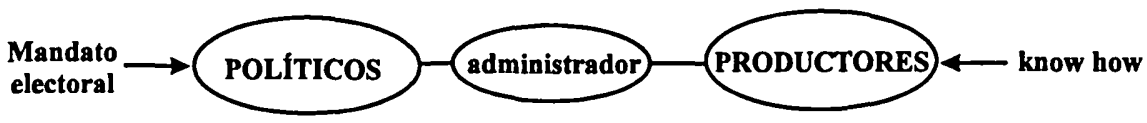

Fuente: El paradigma del cliente en la gestión pública. Sue Rıchards, en revista citada en nota 2, pág. 6.

\footnotetext{
1 De esta forma se expresa el documento contenido en la obra Reflexiones para la modemización del Estado. Edita MAP, Madrid, 1990 (págs. 21 y ss. y 67 y ss.).

2 «El paradigma del cliente en la gestión pública» en Revista de Gestión y Análisis de Políticas Públicas, n. $^{\circ} 1$, septiembre-diciembre de 1994, págs. 5 y ss.
} 
El anterior paradigma se apoyaba en políticas incrementalistas del gasto público, no fundadas en la capacidad de desarrollo económico de los correspondientes Estados, lo cual colisionó gravemente con la crisis de principios de los 70 , poniéndose en entredicho las políticas de crecimiento sostenido y de prestaciones universalizadoras. A raíz de ahí se generó un cambio hacia políticas dirigidas a reducir el gasto público y obtener una mayor eficiencia del mismo. Aparece, así, el paradigma de la Eficiencia, con el que se pretende aplicar mecanismos de mercado que favorecieran una presión sobre los intereses de los productores que provocaban la ineficiencia en las organizaciones del sector público. El Administrador pasó a asumir un papel gerencial, capaz de ejercer esa presión, llevando a cabo los objetivos de los políticos con el menor gasto y con la mayor eficiencia posible. Se precisaba un rol de integrador que crease un nuevo orden alterando el equilibrio entre los políticos y los productores del servicio público (los profesionales y el resto de miembros del personal), lo que en ocasiones comportaría cambiar las pautas de trabajo y, en otras, disminuir los estándares del servicio. Se podría decir que en este paradigma se encontraría el marco actual de las Administraciones públicas, al menos en nuestro país.

\section{FIGURA 2. El paradigma de la eficiencia}

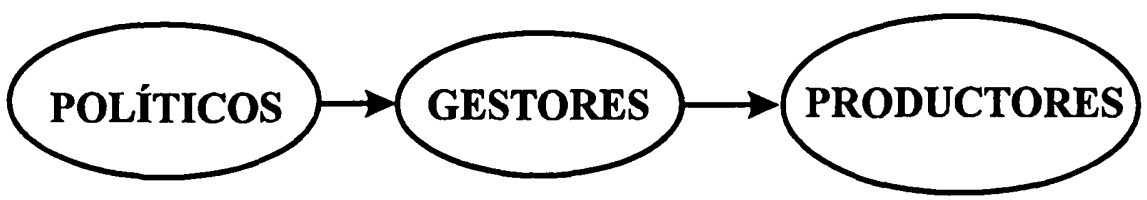

Fuente: Sue RichaRDS en obra citada pág. 7.

Y en la fase final de la evolución llegamos al paradigma del Cliente, hacia el cual se orienta la gestión pública, lo cual sería consecuente con la idea de aprendizaje del sector privado. El concepto del «cliente» comportaría un cambio positivo en la cultura administrativa, el objetivo pasa a ser la mayor calidad en el servicio y hacia él debe orientarse la Administración mediante un trabajo común por parte de gestores y productores. En este marco aparece el Informe de la OCDE sobre la Administración al servicio del público (1987). Se pretende que la Administración pase a caracterizarse por un enfoque interrelacional entre diferentes actores, que coadyuven a la definición de las políticas y objetivos públicos. Podríamos decir que en este paradigma se centra, en nuestro país, la ola modernizadora de la gestión pública, sin que todavía se halla llegado a implementarlo. 
FIGURA 3. El paradigma del cliente

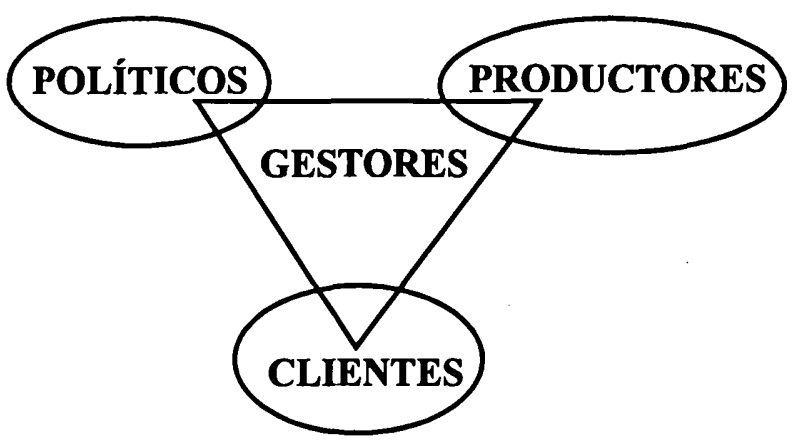

Fuente: Sue RiCHARDS, obra citada pág. 9.

«Su idea de una Administración Pública que trabaje para la gente, sin procedimientos inútiles ni despilfarros, libre de normas y trámites burocráticos absurdos, sigue siendo el catalizador de todos nuestros esfuerzos». (Al Gore en escrito dirigido a Bill Clinton con la remisión del Informe del National Performance Review. 1993).

Como colofón de este capítulo, hay que decir que la idealización de la gestión empresarial del sector privado, a través de los conceptos de excelencia, eficacia, eficiencia, motivación, comunicación, calidad, gerencia participativa, y servicio al cliente, trasladados a la gestión de las organizaciones públicas, no es la panacea, que cual varita mágica resolverá todos los males reales e ilusorios. El modelo de Estado burocrático continúa siendo relevante en aquellos ámbitos donde los poderes públicos necesitan hacer algo más que simplemente escoger entre un menú de bienes y servicios, cuyos orígenes se desarrollan fuera de su control. En todo caso, el debate que se genera sobre el cambio en la acción de gobierno debe ir más allá del estrictamente organizativo, debe ser un debate constitucional, que afecte a los propios fundamentos y capacidades del Estado y de la política y se materialice en los cambios normativos que corresponda ${ }^{3}$.

3 Patrick Dunleavy y Christopher Hood, «De la Administración Pública tradicional a la nueva gestión pública. Ensayo sobre la experiencia modernizadora de diversos países desarrollados» en Revista de Gestión y Análisis de Políticas Públicas, n. ${ }^{\circ}$, mayo-agosto 1995. Estos autores hacen un análisis de diferentes cambios estructurales, competenciales y normativos, en diferentes organizaciones públicas, para modernizar las Administraciones públicas. También Luciano Parejo en «La eficacia, principio de la actuación de la Administración», Eficacia y Administración. Tres estudios, págs. 36 y ss., postula la especificidad de la gestión pública, por la existencia de valores constitucionales que impiden una traslación idealizada de los valores y modos de gestión privada. 


\section{FIGURA 4. Entorno para un debate sobre la orientación y capacidad del Estado en una sociedad cambiante}

ESTADO DE DERECHO

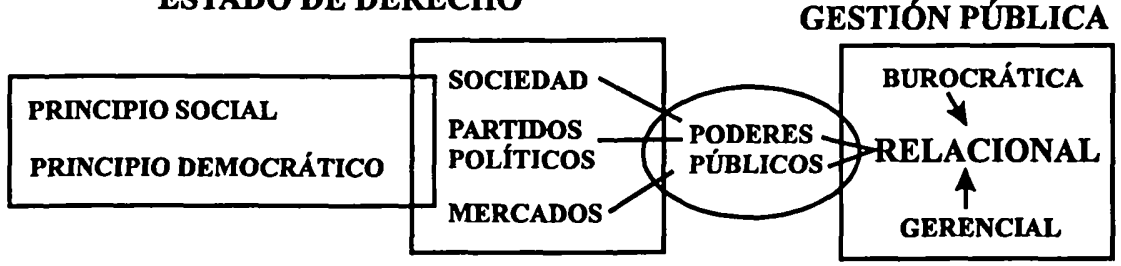

Elaboración propia.

«La Administración y los Sindicatos consideran que la modernización es un proceso gradual, que requiere perseverancia, y que puede implicar reestructuraciones administrativas y orgánicas, introducción de nuevos sistemas y técnicas de gestión, descentralización de funciones, obtención de resultados en la prestación de servicios y dignificación de la figura del empleado público..., sin menoscabo de las necesarias consultas con los interlocutores sociales en los ámbitos correspondientes sobre aquellos aspectos que puedan incidir en la prestación de servicios públicos esenciales. Tales características aconsejan tratar el citado proceso con un horizonte temporal superior al año.

* La organización del trabajo debe responder adecuadamente a la satisfacción de las necesidades de los ciudadanos, y facilitar la comunicación de la Administración con los mismos.

* A fin de satisfacer de manera ágil, eficaz y eficiente las demandas de la sociedad en relación con los servicios públicos de la Administración, las partes se comprometen a mejorar la calidad de aquéllos y a implantar indicadores de gestión en los diversos departamentos y organismos.»

Acuerdo Administración-Sindicatos para modernizar la Administración y mejorar las condiciones de trabajo, firmado en Madrid el 16 de noviembre de 1991, entre el Ministro de Administraciones Públicas y los representantes de UGT, CC.OO., CSICSIF y ELA-STV. Apartados 5, 8 y 9 de la Introducción.

\section{LA FUNCIÓN GERENCIAL}

\subsection{La gestión pública}

\section{Desde los modelos...}

El management no es sólo un proceso de ejecución de políticas separado de su formulación: la eficacia del management público exige unos nexos de unión fuertes entre la formulación de políticas y su implantación... No es sólo un proceso intraorganiza- 
EL GERENTE MUNICIPAL UNA APROXIMACIÓN AL CAMBIO ...

cional, significa el responsabilizarse por el funcionamiento del sistema y, en el management público, en la mayoría de casos, los sistemas son interorganizacionales... La eficacia depende del management global, incluyendo las relaciones entre las organizaciones que componen el sistema, y no únicamente del ajuste riguroso de los sistemas internos... El management público exige la innovación e ideas nuevas más que una continua dependencia con respecto a las prácticas establecidas y a los modelos del sector privado. Se necesita una serie de modelos de management que reflejen las circunstancias de las Administraciones (ministerios dice el autor) y las necesidades de los programas.»

Les Metcalfe y Sue Richards en La modernización de la gestión pública (pág. 314).

...se ha definido el concepto de gestión sobre el modelo burocrático weberiano, caracterizándolo, como función estrictamente ejecutiva de las decisiones políticas, en un proceso intraorganizacional, sometido a un sistema de control jerárquico y ordenado en base a principios generales que objetivan las técnicas de gestión, adoptándose por todas las organizaciones. Éste es el modelo que nosotros conocemos y, que en nuestro marco jurídico se ha materializado en el principio de legalidad, que incide sobre la actuación de las Administraciones de acuerdo con el desarrollo y ejecución de las leyes; en el concepto de competencia administrativa, que limita la actuación de la Administración al alcance de los objetivos que le resultan propios y excluyentes; en el principio de jerarquia normativa y, en el control de legalidad de la actuación administrativa; en el estatuto común de la función pública o el régimen general de la organización y el procedimiento administrativo.

Pero ante este modelo, se contrapone el modelo organizativo gerencial, que a partir de la definición de la gestión pública como la de tomar la responsabilidad por la acción del sistema, implica que se hagan las cosas mediante otras organizaciones (METCALFE y RICHARDS, obra citada, págs. 68 y 69). Se parte de la gestión pública como un proceso político (que afecta a la distribución de poder entre organizaciones y en el seno de las organizaciones), que abarca a la pluralidad de organizaciones actuantes y, que se deriva de la incertidumbre en torno a los resultados de las soluciones propuestas y de la necesidad de aprender constantemente de la experiencia ${ }^{4}$. Es cierto que los dos modelos son válidos y pueden coexistir, según la naturaleza del servicio público (para todo el sistema de recaudación fiscal, es perfectamente válido el primer modelo), pero, de la adaptabilidad a las condiciones y resultados de los servicios, podremos observar que la gestión de políticas públicas no siempre es un proceso ejecutivo mecánico (como ya apuntaba H. Simon en 1957), puesto que en la

4 K. Etxebarría Ariznabarreta en «El cambio y la gestión del cambio en la Administración Pública -Cambio planificado vs. Inercia administrativa-», en la obra colectiva Modermización administrativa, Instituto Vasco de Administración Pública, Oñati, 1989, realiza una explicación más detallada, relacionando las diferentes posturas doctrinales en materia de gestión. 
práctica de numerosas políticas públicas, la ejecución se hace inseparable de la elaboración, y ello se ve claro en aquéllas en que la ejecución comporta un amplio margen de discrecionalidad. Por otro lado, la gestión pública se configura cada vez más como un proceso interorganizacional, donde intervienen organizaciones públicas y privadas (en este sentido METCALFE y RICHARDS, 1987). Proceso que impide el control jerárquico, y comporta que las organizaciones no subordinadas jerárquicamente recurran a fórmulas de influencia y persuasión que harán de la gestión un proceso de negociación permanente (así se expresaba INGRAM en 1977). También, se tiende a especializar y profesionalizar cada vez más las organizaciones, y en este caso, las relaciones no pueden basarse en la autoridad, sino que lo deben hacer en el conocimiento y la experiencia. Por último, frente a los principios universales de gestión, se afirman las teorías de contingencia que defienden la adaptación organizacional a las condiciones de su entorno singular (LAWRENCE y LORSCH, 1967). En esta línea encajan las políticas que buscan en fórmulas de personificación privada, la prestación de servicios, llevando a cabo lo que se ha dado en conocer la huida del Derecho administrativo.

La Administración Pública no puede dejar de entenderse como un poder, tiene potestades, prerrogativas, un marco muy definido que monopoliza en base al interés público, materializando perfectamente los principios social y democrático del Estado de Derecho, siendo su misión la prestación de servicios. Servicios que presta a un ciudadano-persona jurídicalcliente, con derechos a proteger y la posibilidad de una participación activa en la propia definición y gestión de los mismos.

En este entorno el modelo de gestión pública que apliquemos debe permitir la definición de estrategias organizativas para prestar dichos servicios, orientándose hacia el resultado final de la actividad y no hacia las garantías procedimentales (si bien que éstas serán un instrumento, no el fin, para proteger el principio de igualdad y no discriminación), de esta forma se podrá medir y evaluar el servicio producido y la satisfacción del clientelciudadano-persona jurídica sobre los resultados. Ello requiere la implicación de los productores del servicio (los empleados públicos), que deben pasar a ser parte responsable en la creación de los mismos, para tomar conciencia de que son co-productores, en una situación interrelacional con otras unidades administrativas, o gestores con otras organizaciones o con los receptores-usuarios. En este entorno los productores se deben caracterizar por una adaptabilidad permanente, para ajustarse a la diversificación y aumento de las demandas sociales, e implementar el grado de satisfacción del usuario, mediante la creación de la calidad en el servicio como valor de la organización.

Este modelo de gestión, debe comportar una redistribución estructural interna de la Administración, diferenciando tres círculos organizativos, uno in- 
EL GERENTE MUNICIPAL UNA APROXIMACIÓN AL CAMBIO ...

terno en el que se encontrarán las unidades y servicios que se prestan intraorganizativamente; uno externo, en el que se encontrarán las unidades y servicios que se interrelacionan con el exterior (clientes/ciudadanos-organizaciones) $y$, una tangente, que uniría los dos círculos, y en la que se encontrarían las unidades o servicios a los que se les encomiendan funciones de control y garantías. En cuanto al proceso de trabajo interno de la organización, la prestación de servicios exige procesos flexibles, creativos $e$ innovadores; y, en buena medida, un trabajo en equipo o cooperacional, que, sobre la base de la responsabilidad, permita, mediante las correspondientes delegaciones, que en todos los niveles se puedan tomar decisiones, con un grado elevado de autonomía, lo que comportará la formación constante, para mantener un alto grado de cualificación por los empleados, en sus diferentes niveles, para conseguir, mediante la adhesión, la cohesión de las diferentes unidades o servicios, sobre unos objetivos comunes, correspondientes a las políticas públicas establecidas.

En este sentido se manifiesta el «Informe Abril», como se denomina al informe redactado por la Comisión de Análisis y Valoración del Sistema Nacional de Salud español ${ }^{5}$, requiriendo para las organizaciones públicas la previsión de mecanismos que consigan incorporar el mayor grado de responsabilidad a los gestores del sistema, con el fin de alcanzar una mayor eficacia en el uso de los recursos humanos y materiales dentro de un marco de autonomía responsable: responsabilidad, eficiencia, autonomía; la creación de las bases para que el sistema pueda funcionar con mayor satisfacción subjetiva de los usuarios de los servicios; la promoción de una conciencia de coste, tanto para el profesional público, como para el ciudadano; la creación de estructuras capaces de ajustarse flexible y autónomamente en su gasto, a las autorizaciones presupuestarias; la obtención de un mayor grado de participación activa en la vinculación al proyecto y motivación del personal.

Para finalizar habría que añadir que, en los últimos años, la mayoría de paises occidentales han puesto en marcha ambiciosas propuestas para transformar sus sistemas administrativos (estrategia de eficiencia en Reino Unido, renovación del sector público en Francia y Suecia, desburocratización en Alemania, descentralización en Holanda, restauración administrativa en Dinamarca...) sobre políticas de modernización administrativa, que comportan una nueva forma de concebir la Administración. Las medidas en que ello se ha concretado se han basado en diferentes actuaciones, como la descentralización de las funciones ejecutivas en las unidades de gestión; la divisionalización de las funciones ejecutivas en entidades autónomas (agencias, entes instrumenta-

5 Citado por Francisco LoNGo en «Nuevos modelos de gestión en la Administración local» (pág. 27), trabajo incluido en el libro Nueva Gestión local. Modernización municipal en Alcobendas (1). Editorial Popular, Madrid, 1993. 
les); la introducción de sistemas de dirección por objetivos; la utilización de los presupuestos como instrumentos de gestión; el desarrollo de sistemas de planificación y control de gestión; la evaluación individualizada del rendimiento y estímulo económico de la productividad; la modificación de esquemas clásicos de responsabilidad política, asumiendo la legitimidad de las funciones de gestión; el establecimiento de cauces de cooperación entre el conjunto de entidades públicas y privadas definidoras y ejecutoras de políticas públicas; promoción del cambio de valores dominantes en la organización, sustituyendo la cultura burocrática por otra basada en la responsabilidad de los productores de servicios; establecimiento de sistemas de evaluación de programas y políticas públicas, en entornos de mejora continua con instrumentos de control de gestión ${ }^{6}$. Pero entre estas actuaciones, cada vez más presentes en el modelo de gestión pública gerencial predominante en el entorno socio-político occidental, se encuentra a faltar, de una forma generalizada, la orientación hacia la calidad en la prestación de servicios, mediante un alto grado de satisfacción de las necesidades de la sociedad, la cual sería, actualmente, la asignatura pendiente.

\section{Desde las técnicas de gestión...}

"Cada época tiene sus problemas y plantea los instrumentos para hacerles frente».

Joan Prats, en Govern i Administració a les grans ciutats, 1987.

El mercado, esa fuerza oculta que todo lo mueve ha sido motor, en la gestión empresarial privada, de un constante desarrollo de técnicas de gestión, en absoluto homogéneas para los diferentes sectores económicos o sociedades, en una constante tendencia a la diversificación de técnicas. Ello ha conllevado una literatura abundantísima, principalmente de origen anglosajón y una gran proliferación de Escuelas de negocios, donde se analizan las experiencias, sobre las técnicas del caso, y se difunden con gran rapidez entre ejecutivos ávidos de soluciones mágicas que les permitan mejorar la posición de su empresa en el mercado (espacio de intercambio económico donde se interaccionan sujetos sobre el equilibrio/desequilibrio de la oferta y la demanda), así como su competitividad y resultados. Esta fuerza oculta requiere de las empresas que identifiquen o seleccionen los mercados o segmentos de mercado que les ofrecen mayor potencial de beneficios; que puedan satisfacer las demandas y preferencias de los clientes que forman parte del mercado al que se dirigen, proporcionándoles bienes y servicios que para el cliente tengan valor; que diferencien su

6 Para un estudio más pormenorizado de la evolución del proceso de modernización en Europa, ver $\mathrm{K}$. ETXEBARrla ARIZnABARReta, «Los procesos de modernización de las Administraciones públicas en Europa» en documentos ESADE, programa en función gerencial, curso 1995-1996. 
oferta, haciéndola más atractiva que las de sus competidores, en cuanto a características, precio, etc...; que rentabilicen sus inversiones mediante gestión eficiente. En caso contrario, el mercado les acabará echando. En este contexto las técnicas de gestión empresarial se caracterizan por la primacía de la lógica de adaptación al entorno, que comporta una adaptabilidad constante de las condiciones internas y externas de la empresa, para responder a las demandas de su mercado. Por otro lado, se dan en modelos de decisión racional, con un decisor único capaz de ordenar sus preferencias, formular objetivos no contradictorios, y evaluar las distintas alternativas así como la actuación presente de la organización en base a dicho sistema integrado de objetivos (SCHARPF, 1978 y Metcalfe, 1990). También existe una clara orientación hacia la cuantificación, debido a que se actúa en un contexto abundante en información tanto de la competencia, como de la disponibilidad y coste de los distintos recursos empleados, por lo que se otorga primacía al cálculo y la cuantificación. Por último, se dan con un marcado carácter intraorganizativo, puesto que los resultados que obtiene la empresa están en función de sus propios recursos, de sus habilidades y del esfuerzo realizado frente a sus competidores ${ }^{7}$.

Por otra parte la gestión pública se contextualiza en un marco específico, que se caracteriza: a) por la sustitución del mercado, como sistema de consecución de recursos, por el proceso político (elección periódica de gobernantes, sistema fiscal obligatorio y coactivo, definición, priorización y equidistribución política de servicios y recursos, fragmentación de la autoridad, interrelaciones entre diferentes agentes); b) por el carácter de poderes públicos de la Administraciones (sus objetivos están fijados por la ley, a la cual están sometidas —entendiendo la ley como norma-, no por la organización, se les atribuye autoridad, que materializan en la formulación de políticas públicas y la regulación de la actividad privada y de las relaciones públicas, siendo su legitimidad constitucional, como instrumento del Estado para la consecución de sus fines); c) por la diferente naturaleza de los procesos de creación de valor por parte del sector público (valor que crea en la relación con la sociedad, en la externalización de los programas de actuación o actividad a una generalidad mayor a los usuarios directos, en la extensión de la capacidad protectora y preventiva sobre la transmisión de la idea de seguridad - pública, vial, ambiental, militar...-, en la elaboración de normas reguladoras, en el refuerzo y protección de los derechos sociales y del interés general); d) por la dificultad de medida del valor creado por las Administraciones (los servicios no se transfieren sobre la base coste-beneficio y consecuente repercusión en un precio de

7 En este sentido y desde el enfoque de considerar las técnicas de gestión empresarial como respuesta a las exigencias del mercado, se encuentra el estudio de Xavier MENDOzA, «Técnicas gerenciales y modemización de la Administración Pública en España» en Revista Documentación Administrativa, n. ${ }^{\circ} 223$, julio-septiembre, 1990. 
todos los costes directos e indirectos vinculados, lo que un programa o actividad pública produce, se diferencia de su resultado en que el valor lo aporta la percepción social sobre la respuesta a la necesidad creada).

Al no existir un desarrollo de técnicas de gestión pública, lo que se hace es adaptar a la especificidad pública las técnicas de gestión empresarial. Dichas técnicas, a cuyo estudio nos remitimos en cualquier manual de gestión empresarial, las podríamos estructurar de la siguiente forma ${ }^{8}$ :

- Técnicas de dirección global de la organización. Se caracterizan por considerar la organización en su conjunto sobre la base de la perspectiva operativa (sobre rendimiento global de la organización) y la perspectiva estratégica (que favorecerá la anticipación y adaptación a los cambios del entorno).

- Técnicas específicas de apoyo al ciclo de gestión de los objetivos organizativos globales (planificación-ejecución-control).

- Técnicas de desarrollo de habilidades directivas. Recogen la evolución existente desde la capacitación para la función directiva, hacia la capacitación del liderazgo del cambio organizativo.

\subsection{El perfil del directivo}

En primer lugar, no podemos obviar plantearnos qué es dirigir e irremediablemente nos viene una definición funcional, caracterizada por la integración de conceptos que se encontrarían en el ámbito de la autoridad suficiente, como planificar, organizar, decidir, coordinar, controlar en el proceso, evaluar resultados, priorizar, comunicar (motivar, corresponsabilizar), monitorizar (definir estrategias globales, objetivos, políticas), mandar y conceptos que se encontrarían en el ámbito de la responsabilidad, del conocimiento de la materia, como resolver problemas, formar, liderar, negociar, representar, observar. Pero las investigaciones realizadas (como la de H. MiNTZBERG en Canadá, citada por J. PRATS, en obra referenciada), revelan que las grandes funciones definidoras de la dirección pública son la relación interpersonal, el manejo de información y la de decidir, siendo las anteriores un aspecto menor de su labor. Por otro lado, John CotTER, en un estudio de la Universidad de Harvard sobre gerentes públicos americanos, determina que lo básico en su eficiencia es la

\footnotetext{
8 Xavier MENDOZA, en obra referida en nota anterior, realiza, en las págs. 282 y ss., un estudio muy interesante sobre la idoneidad del diseño de las técnicas gerenciales para dar respuesta a los problemas de gestión de las organizaciones públicas.
} 
EL GERENTE MUNICIPAL UNA APROXIMACIÓN AL CAMBIO ..

capacidad para llenar la agenda de decisiones, discernir lo que son los temas estratégicos y la capacidad de construir la red de contactos internos y externos que hace viable la implementación de las decisiones, mediante una comunicación continuada con una amplia red de interlocutores de dentro y fuera de la organización para la definición de la agenda y negociación de contactos.

Pero estos estudios se olvidan de un factor importantísimo del directivo, que es su propia percepción de considerarse como tal, y no como un técnico o gestor. En este trabajo al gerente se le conceptúa como directivo, porque se entiende como tal a quien en las Administraciones desempeñan cargos $u$ ocupan puestos de carácter ejecutivo, asumiendo la dirección de los procesos a través de los cuales se ponen en práctica las políticas y se producen los servicios públicos, situados al frente de unidades o entes específicos $e$ investidos de autoridad jerárquica y respondiendo e interactuando junto al nivel político, de parcelas concretas de la actuación administrativa ${ }^{9}$. La función gerencial exige un directivo profesional, que vaya más allá de lo que sería un simple administrador de recursos (financieros, jurídicos, de personal, organizativos...), o un simple gestor con funciones ejecutivas sobre las políticas públicas (como lo caracteriza B. KLIKSBERG en La gerencia pública necesaria, 1985).

Se requiere un emprendedor en un marco de gestión relacional:

- Que participe activamente en la definición e implantación de políticas públicas, desde el asesoramiento, la formulación, la ejecución y la integración.

- Que facilite estrategias de cohesión e interrelación entre los diferentes agentes que interactúan en el ámbito de la gestión pública, en un contexto político, legal, social, tecnológico y financiero.

- Que detecte los cambios en el entorno para que mediante la prospectiva y los planes estratégicos se puedan modificar las políticas públicas, facilitadoras de la adaptación de la organización a un entorno en constante cambio.

- Que sepa manejar situaciones dinámicas inciertas y con demasiada frecuencia ambiguas.

9 Definición dada por Francisco Longo, siguiendo a H. MinTzBerg en «Políticos, Directivos y Sindicatos como actores de la gestión de recursos humanos en las Administraciones públicas» en separata Papers ESADE, n. ${ }^{\circ}$ 148, julio, 1996, pág. 5. 
- Que sepa trabajar en equipo consiguiendo el máximo rendimiento y satisfacción de las personas y los grupos.

- Que gestione eficientemente y consiga atraer recursos externos (financieros y prestacionales - mediante la gestión por voluntariado u otras organizaciones-) para lograr los objetivos y políticas públicas.

En este marco, el perfil del directivo aparece caracterizado por su orientación a la acción y a la consecución de resultados, su capacidad de interlocución con el nivel político, su capacidad de iniciativa y de asunción de riesgos, por saber negociar y dirigir equipos humanos, y se concreta en la cualificación y competencia que las organizaciones públicas requieren de él en relación a sus conocimientos, habilidades y conductas.

Pero, este perfil es difícil de encontrar y, en todo caso requiere de una formación permanente, la cual, en la actualidad, no se encuentra en la oferta de ninguna escuela de negocios o de administración pública. Con lo cual, se puede afirmar que es un perfil de desarrollo continuo, sobre la base, ya apuntada anteriormente, de la percepción que tenga el directivo de sí mismo, y por otro lado de la apuesta de los gobernantes políticos en que ello se lleve a cabo. Pero, no se puede olvidar que el directivo lo será, más por su talante, aptitudes, empatía y capacidad de interrelacionarse, que por la formación que haya recibido, y, ese know how personal sólo se puede conocer percibiéndose a partir de la experiencia práctica en la gestión de la incertidumbre, que caracteriza la gestión pública. Cuantas Administraciones envían a sus técnicos y gestores, a programas MBA o gerenciales, para que luego sigan gestionando como administradores de recursos en modelos burocratizados, sin que sepan aportar criterios de mejora y modernización, presuntamente aprendidos. Los responsables políticos no deben temer buscar su máximo/s directivo/s allá donde se encuentren, sea dentro o fuera de la organización, y mantener una estrategia de formación adecuada, independientemente del coste que ello comporte, lo importante es que crean en el perfil aqui apuntado y apuesten por el consecuente cambio organizativo implantando un modelo gerencial de gestión, de otra forma sólo construirán edificios de barro que, antes o después, el entorno acabará derrumbando. Y ello es así, porque no existe una racionalidad teórica de la organización, sino una capacidad de sus dirigentes para manejar situaciones de incertidumbre.

«El gerente es un politécnico, requiere de la confianza del responsable político y ha de sintonizar con el programa político. Es el hombre/mujer del cómo, mientras que el político lo es del qué. Su reto está en no colisionar en la suma de esfuerzos, evitando el solapamiento» (Josep M. Procházka, gerente distrito de ciutat vella. Barcelona, febrero 1997). 
EL GERENTE MUNICIPAL UNA APROXIMACIÓN AL CAMBIO ...

Respecto al político, no existe una separación funcional clara, ya que es consustancial al perfil de directivo que aquí apuntamos, no su identificación política con el gobernante, sino la capacidad de gestionar de forma fluida la comunicación entre ambos niveles. El directivo público estará implicado en una estrecha relación con el respectivo entorno político, del que recibe su autoridad, en la medida en que participa en la definición y ejecución de políticas públicas, para dar respuestas a las demandas sociales y rentabilizar los recursos públicos, por el hecho de gestionar el entorno en el cual se desarrollan esas políticas, $y$ en tanto en cuanto es reponsable de evaluar y analizar los programas que gestiona.

«Cuanto más rica, compleja e interdependiente se hace una sociedad, mayor es la necesidad de acción de los poderes públicos y más insufrible y costosa resulta la incompetencia de los agentes públicos. Que nadie se engañe: la necesidad de Administración Pública va a más; pero la Administración burocrática va a menos. Lo que necesitamos no es más Administración de la que tenemos, sino más Administración capaz de prever el desarrollo, las necesidades públicas, estimular a los agentes privados, concertarlos, disciplinarlos, motivar y responsabilizar al personal, crear ambientes cooperativos de trabajo, desarrollar relaciones interadministrativas positivas, cuidar la eficiencia de los servicios, orientarse ante todo hacia la satisfacción al ciudadano y producir el mínimo normativo necesario dirigido a encauzar y disciplinar, pero no a bloquear los comportamientos sociales. Se trata, en síntesis, de hacer evolucionar el modelo organizativo burocrático de las Administraciones públicas hacia el modelo de organización gerencial, que es el único que puede dar respuesta a la "crisis del Estado" y realizar los valores constitucionales del Estado social y democrático de Derecho.»

Joan Prats, en La formación para la Administración local en los 90, 1989.

\section{EL GERENTE MUNICIPAL}

«El gerente municipal nace como resultado de la inadecuación administrativa a las nuevas necesidades y por una necesidad de especialización en la gestión que no poseen los políticos. Se pretende que asegure el funcionamiento organizativo, adaptándolo a las nuevas tendencias y a las necesidades de los servicios, mediante una coordinación eficaz de los mismos. Para ello debe disponer de gran autonomía en la definición de las funciones internas del Ayuntamiento, participando en la definición de las políticas públicas, por lo que deben formar parte del equipo directivo del gobierno municipal, identificándose con su proyecto de ciudad y vertebrando el que la organización actúe de acuerdo con los objetivos establecidos.»

Jaume Bosch, Vicepresidente primero de la Diputación de Barcelona. Febrero de 1997. 


\subsection{Introducción}

Aunque hablar de gerente en el ámbito municipal nos parezca una novedad revolucionaria, ante la cual suelen surgir resistencias inmediatas, tanto desde los responsables políticos como desde las estructuras orgánicas de los Ayuntamientos, el Estatuto municipal de 1924 (promulgado el 8 de marzo, con rango de Ley) aprobado en la Dictadura de Primo de Rivera, y que en muchos de sus aspectos era ciertamente avanzado y hasta progresista, ya preveía la posibilidad de establecer en Municipios de determinada entidad, el sistema de gobierno municipal por Comisión o por Gerente. Es importante recoger la justificación que sobre este hecho se hacía en la Exposición de Motivos, donde se decía que «el Gerente representa el máximo avance a la ardua empresa de cohonestar la democracia con la eficacia, y parte de la base de que cualquier Municipio constituye un negocio, el mejor negocio para el pueblo si recibe una buena administración, por lo que su gestión no debe diferir de la que mercantilmente tengan los negocios privados». En el gobierno municipal por Gerente, éste era designado libremente por el Ayuntamiento (formado por Concejales electos de representación corporativa) y asumía plenos poderes en la gestión de los servicios de interés comunal, manteniendo la Corporación un Alcalde-Presidente, al mero efecto de dirigir las sesiones municipales (art. 146). Los requisitos para implantar esta figura eran que el municipio tuviera más de 50.000 habitantes, o cuyo presupuesto de gastos excediera de las 50 pesetas anuales por habitante, que se acordara previa propuesta del vecindario mediante referéndum y que lo aprobara el Gobierno de la nación (art. 144).

En nuestra historia reciente, aparecen instituidos los principales funcionarios locales con la creación de los denominados cuerpos nacionales de Administración local, modelados en el Estatuto municipal promulgado en la Dictadura del general Primo de Rivera y en su Reglamento de 23 de agosto de 1924 (en el cual se acababa de definir funcionalmente una figura que ya existía, rodeándose el cargo de garantías y responsabilidades que le daban una gran autonomía). Dicho marco normativo se motivó en su origen, en la extensión del control del Estado al nivel administrativo local, control que a partir de la Dictadura del general Franco se completaba con el nombramiento de los Alcaldes, a través del Gobernador civil (actuando como sus Delegados), y con los Servicios de Inspección. Por otro lado, y con el tiempo, se pretendió, asimismo, una mayor independencia en el ejercicio de las funciones profesionales, definiéndose normativamente un perfil de funcionarios preparados para tareas estrictamente burocráticas y capaces de cumplir con una legalidad estrictamente formal. Su capacitación era esencialmente jurídica, funcionando con criterios ajustados únicamente a esa racionalidad. En esta configuración se hizo prevalecer una figura, como máximo directivo municipal, que era la del Secretario General. El Decreto de 30 de mayo de 1952 les otorgaba el carácter de miembros 
EL GERENTE MUNICIPAL UNA APROXIMACIÓN AL CAMBIO ...

de la Corporación, pudiendo asistir a todas las sesiones con voz, e intervenir con criterios de oportunidad y argumentos metajurídicos. Asimismo, ejercían la jefatura directa del personal de la Corporación y la dirección inmediata de los servicios públicos (a partir del Texto refundido de régimen local de 1955), no siendo hasta el Texto articulado parcial de 1977, que no se limitan sus funciones al preverse que las mismas las realizarán «bajo la superior autoridad del Presidente de la Corporación». Y así se mantiene esta situación hasta la Ley de Bases de 1985 y el Texto refundido de 1986, que derogan toda la normativa anterior, $y$ atribuyen al Alcalde la jefatura superior de todo el personal, facultad que puede delegar. Pero no diciéndose nada de la jefatura directa, que se puede atribuir por desconcentración, con capacidad de dictar actos administrativos. La historia de la Administración municipal, hasta época muy reciente, y salvo excepciones, sólo ha conocido una organización burocrática organizada según el modelo weberiano, ya explicado en su momento, es decir, orientada hacia el procedimiento y el cumplimiento de la legalidad, y estructurada sobre la Secretaría General y la Intervención General, pasando a desempeñar un papel más importante la primera, hasta finales de los ochenta, en que las necesidades financieras han hecho ir prevaleciendo a la segunda.

Pero no sólo han jugado un papel básico en la estructuración de las organizaciones locales, sino que también lo han tenido y, en buena medida lo siguen teniendo, en las decisiones que adoptan los responsables políticos (miembros corporativos), a través de los correspondientes órganos. Para ello, fue inicialmente determinante la función de «advertencia de ilegalidad» - hoy ya desdibujada en los informes preceptivos en determinadas materias-, la posibilidad de solicitar la intervención en determinados órganos - cuando sea dudosa la legalidad de los acuerdos a adoptar-, y la fiscalización económico-financiera -en aspectos formales-. El modelo de burocracia weberiana comporta que estos altos técnicos, sin sentirse directivos, con una gran movilidad que afecta críticamente a las Corporaciones, y sin estar legitimados más que por una oposición que da derecho al cargo, complemento de destino y a las funciones atribuidas legalmente (cosa que no ocurre prácticamente en ningún otro cuerpo, sea de la Administración que sea), tienen la posibilidad de condicionar enormemente la definición de las políticas públicas. Y ello ocurre cuando ocupan una posición de neutralidad (concepto que no tiene implicación política, sino organizacional, en cuanto a la obligación de la Administración de conseguir los objetivos establecidos sobre la base del principio de legalidad y como garantes de esa legalidad jurídica y presupuestaria), respecto al establecimiento como a la ejecución de esas políticas públicas, neutralidad que, en cambio, no puede tener el resto de personal. Es de destacar que la Administración General del Estado y la de las Comunidades Autónomas están estructuradas sobre la base de directivos que pertenecen a cuerpos generalistas o, a partir de un determinado nivel, son políticos, reservando la función interventora y de control de lega- 
lidad a los procesos de desarrollo de la actividad administrativa, pero no a los procesos decisores de políticas. Así, en el Estado, el Cuerpo Superior de Administradores Civiles ocupa los cargos directivos hasta Director General y los políticos, los superiores a partir de ese nivel, reservando a los Cuerpos de Abogados del Estado e Interventores de Hacienda, los cargos asesores y fiscalizadores, preceptivos o no, pero con funciones que se llevan a cabo una vez ya decididas las políticas públicas correspondientes. Lo mismo suele ocurrir en las Administraciones autonómicas (en Cataluña el nivel político comienza a partir de Director General).

Con este planteamiento no digo que no deban existir estos cuerpos en la Administración local, que en algunas pueden ser necesarios y, en otras, se pueden cubrir con un asesoramiento externo, cuyos costes siempre serán inferiores, sino que se reconsidere la propia figura y sus funciones, la incardinación orgánica que les corresponda, así como su configuración en la organización, que en estos modelos de burocracia maquinal sería como tecnoestructura. Lo que se postula es que sea cạda Corporación la que decida, mediante las técnicas correspondientes de provisión de puestos, y las correspondientes aprobaciones de plantilla y relación de puestos de trabajo, aquellos puestos que se catalogarán de directivos. Ello comportará que en una gran mayoría de Ayuntamientos, sobre todo medianos y pequeños, sin personal suficientemente cualificado y condicionados por los costes que el mantenimiento obligatorio de estos cuerpos conlleva o por la propia cualificación de quienes los ocupan, se hará recaer en ellos el nombramiento como personal directivo, con las funciones correspondientes, la implicación en la definición de políticas públicas y la formación gerencial necesaria correspondiente al perfil del directivo (en la cual deben participar activamente otras Administraciones, como los Consejos comarcales, las Diputaciones, las Comunidades Autónomas y el propio Estado) y, sin que ello se contradiga en absoluto, con el mantenimiento de sus funciones legales (este modelo, que luego se verá, se da en Alemania). Pero, en todo caso, habrá sido la decisión libre de los responsables democráticos de la organización la que se habrá llevado a cabo, decisión que ha de poder comportar también la de su remoción, manteniendo el puesto inicial o el que le correspondiera en la relación de puestos, como ocurre en cualquier Administración en la que se diferencia el puesto de trabajo del cuerpo de referencia. Y, si no creemos en ello, pondremos un lastre importantísimo a la consecución de los propios fines de la Administración, de acuerdo con lo explicado en anteriores capítulos. Es cierto que la doctrina administrativista parte de una desconfianza absoluta hacia una Administración local que se considera inferior, y no mayor de edad e igual en un ámbito competencial diferente, clamando contra un hipotético y constante ataque a la legalidad que se dará si no se la controla. En realidad la desconfianza es hacia la clase política, presuponiendo que siempre hará un uso arbitrario del poder. Por eso se defienden estos cuerpos, como último resorte antes del reconocimiento de autonomía y garantía institucional de estos entes, y no existe una receptividad 
EL GERENTE MUNICIPAL UNA APROXIMACIÓN AL CAMBIO ...

suficien te a la implantación de modelos gerenciales. (Como exponente de esta desconfianza, véase Morell OcaÑa, en El sistema de confianza política en la Administración Pública).

Pero existe una realidad, que la mayoría de funcionarios pertenecientes a estos cuerpos, negocian directamente con los Alcaldes su movilidad y retribución, al margen de las establecidas en los cauces representativos normales para el resto del personal, actúan como máximos directivos, sin sentimiento de pertenencia a la organización, disponen de controles importantes que pueden afectar la actuación municipal (la firma, informe preceptivo, control institucional -bajo el paraguas de únicos intérpretes de la legalidad jurídica o presupuestaria- en un ámbito en el que el juego político se caracteriza por su gran enfrentamiento e instrumentalización del personal) y disponen de privilegios que no existen para el resto del personal (si son nombrados por libre designación - según la regulación dada en la Ley 10/1993, de 21 de abril, que reforma el art. 99 de la Ley de bases-y se les cesa, se les mantendrá un puesto de trabajo correspondiente a su categoría en esa Corporación, cosa que no ocurre con el resto de personal directivo, que ni es considerado funcionario, sino eventual, ni se le mantiene otro puesto; por otro lado, de ellos depende el que se quieran ir o no; el sistema disciplinario les es mucho más favorable que para el resto de personal, ya que también interviene la Administración del Estado...). Y su única legitimidad es haber superado una oposición memorística y el correspondiente curso, donde se les ha exigido una capacitación esencialmente jurídica y procedimentalista, que sólo tiene que ver con una parte de las funciones que desarrollarán, y que en la mayoría de casos no difiere de la misma que se ha exigido a los cuerpos superiores propios de la Administración local.

Como excepción, a esta situación histórica, se encuentra la figura de los Delegados de servicios, que aparece regulada en las Leyes especiales de Barcelona (art. 9 del Decreto 1166/1960, de 23 de mayo) y Madrid en 1960, como colaboradores del Alcalde, realizando una misión complementaria, para la que pueden recibir delegaciones $y$, siendo ellos y no los miembros corporativos los que desempeñan las funciones de jefatura inmediata de una división de servicios. Dichos Delegados formaban parte de la Comisión municipal ejecutiva (órgano de gobierno con competencias administrativas importantísimas en todas las materias), conjuntamente con los Tenientes de Alcalde y los concejales nombrados al efecto, con voz y voto. Asimismo, podían asistir al Consejo pleno, con voz, pero sin voto. Esta figura se generaliza en la Ley de Bases de 1975 y el Texto articulado de 1977, denominándoseles Directores de servicios, pero perdiendo las funciones politécnicas de estas leyes especiales, pudiéndoseles nombrar en cualquier Ayuntamiento, cuando la complejidad de los servicios propios de la competencia municipal así lo aconsejara. Con esta figura se residenciaba en la Corporación la competencia de nombrar a su personal directivo, pero se mantenía la estructura de los 
cuerpos de habilitación nacional. Ello se mantiene hasta el Texto refundido de 1986, que pasa a hablar de personal eventual para ocupar puestos de trabajo directivo, siempre que esos puestos, que se podrán denominar como cada Administración decida, estén incluidos en sus relaciones de puestos de trabajo.

Es muy importante que la Administración local sepa realizar sus expedientes y conozca y aplique la legalidad procedimental y presupuestaria, pero es mucho más importante, por su carácter prestacional $e$ instrumental, como Administración más próxima al ciudadano, que preste bien sus servicios, consiguiendo la satisfacción de los ciudadanos/clientes; que gestione bien sus recursos económicos, para que no disponga de la presión fiscal como único o principal medio financiero; que racionalice sus estructuras, para no condicionar su futuro; que implique a su personal, para conseguir una mejor aplicación de las políticas públicas..., y para ello, necesita tener directivos, profesionalizarlos e implantar modelos de función gerencial.

\subsection{El gerente local a nivel comparado}

Esta figura se ha gestado de forma diferente a lo largo del tiempo. En los años 50 y 60 los grandes focos de atención en las Administraciones locales se centraban en la planificación y la programación del desarrollo urbano a largo plazo, concretándose en nuestro entorno más inmediato, en la ordenación urbanística supramunicipal, la programación de servicios y el fortalecimiento de la capacidad ejecutiva municipal. A partir de los 80 , la focalización se desplaza hacia la contención presupuestaria, derivada de las constricciones financieras, y hacia el incrementalismo prestacional, en un entorno revolucionado per las nuevas tecnologías. De un estudio realizado sobre las ciudades de Colonia (Alemania), París (Francia), Londres y Birmingham (Gran Bretaña) y Nueva York y Boston (EE.UU.) ${ }^{10}$, se destacan diferencias importantes respecto a los modelos organizativos sobre los que se asienta nuestra realidad. Los Consejos municipales (plenos) suelen tener un número de miembros superior, se reunen con más frecuencia, estructurándose por comisiones permanentes que asumen la obligación de debatir, formular y hacer el seguimiento de un área concreta de la política de la ciudad. Los Consejeros o Concejales se dedican a la definición y seguimiento de las políticas y el mantenimiento de las relaciones con los ciudadanos, no asumiendo responsabilidades ejecutivas, ni siendo los directores ejecutivos de las políticas, funciones que corresponden a personal técnico, que suele ser de confianza política del grupo mayoritario.

10 Govern i Administració a les grans ciutats (Documents de Treball per a la Carta Municipal). Edita Ayuntamiento de Barcelona, 1987. Autores Miquel Botella, Montserrat VendRelL, Montserrat CuCHI. LLo y Joan PRATS. 
EL GERENTE MUNICIPAL UNA APROXIMACIÓN AL CAMBIO .

En Colonia, al frente de la estructura profesional se encuentra un gerente, elegido por el Consejo Municipal, que asume la función de jefe de la Administración municipal, funcionario temporal nombrado para un período de 8 años, y que puede reelegirse. Sus funciones son las de dirección ejecutiva de la Administración y la de Secretario General (que prepara los acuerdos y resoluciones del Consejo municipal y de las Comisiones, encargándose de su ejecución), con la posibilidad de formular advertencias de ilegalidad, con efecto dilatorio. Por otro lado, los órganos de gobierno le pueden delegar competencias. Junto a él, existen los Directores de Área funcional, también nombrados por el Consejo como funcionarios temporales. Con el gerente forman el vértice de la Administración municipal ejecutiva, que se supone técnico y neutral respecto a los partidos representados en el Consejo. En París, el modelo no difiere mucho del nuestro, el Alcalde asume las funciones ejecutivas, si bien la dirección ejecutiva de las áreas centrales, funcionales o sectoriales no se atribuyen a los Concejales o Alcaldes adjuntos, sino a técnicos nombrados por él, que suelen pertenecer a Cuerpos funcionariales. En Gran Bretaña, y como modelo general en la Administración local inglesa, también existe la figura de un gerente, denominado chief executive officer, que es nombrado por el Consejo, configurándose como Jefe de la Administración municipal, principal asesor del Consejo y del Leader del Consejo (figura que sería similar a la del Alcalde que conocemos, correspondiendo al líder del grupo político que tiene la mayoría en el Consejo y, que es el que en última instancia conforma los acuerdos referentes a la política global y vertebra las relaciones entre el personal político y administrativo, en una relación muy estrecha con el gerente). Este modelo responde a un cambio reciente (Reforma 1972), que ha comportado la sustitución del más alto funcionario local, el Secretario municipal, por esta figura, así como el establecimiento de un equipo de gestión dirigido por el gerente, que al mismo tiempo actúa de equipo asesor de la Comisión principal de, entre las que se divide el Consejo, y que asume la formulación de la política general, así como la resolución de asuntos concretos, ya que tanto a las Comisiones, como al Gerente, como a los Directores ejecutivos, el Consejo les delega la mayoría de sus competencias. El reclutamiento del gerente se suele hacer entre personas procedentes de las organizaciones privadas y con fommación generalista. Por último, en EE.UU., se dan tres modelos de gobierno municipal. Por una parte el que se denomina por Consejo y Alcalde. En este modelo se elige separadamente al Alcalde y a los miembros del Consejo. El primero tiene el poder ejecutivo y el segundo el normativo y el de formulación de políticas generales. La presidencia del Consejo no tiene por qué corresponder al Alcalde. En este modelo existen dos variantes. La primera hace referencia a la figura del Alcalde fuerte, que se suele dar en las grandes ciudades, concentrándose en él todos los poderes ejecutivos, la posibilidad de proponer reformas legislativas, la preparación del Presupuesto de la ciudad y el derecho de veto sobre acuerdos del Consejo. Nombra libremente a todos los responsables departamentales. En esta variante suele existir la figura del gerente, chief administrative officer, que ac- 
túa con poderes muy limitados, nombrado por el Alcalde y, con funciones de coordinación o dirección administrativa. La segunda variante se conoce como la figura del Alcalde débil, caracterizado por ser el Consejo el que controla el Presupuesto; reducirse la competencia de nombramiento de directivos, que pasan a ser nombrados por el Consejo algunos, otros por el Alcalde, con control o no del Consejo e, incluso, en algunas ciudades, eligiéndose mediante sufragio. Esta variante se suele dar en municipios pequeños. El segundo modelo sería el de gobierno por Comisión, en el que las funciones legislativas y ejecutivas se atribuyen a este órgano, formado, en la mayoría de los casos, por cinco miembros, elegidos directamente por los ciudadanos. Los comisionados, además, son los jefes de los principales departamentos. También existe la figura del Alcalde, elegido por los comisionados o, directamente por sufragio, pero es un cargo protocolario. Este modelo es inusual y ha sido muy criticado por tender hacia la despersonalización y ausencia de responsabilidad, siendo muy ineficiente, al no existir coordinación entre los diferentes Departamentos. Se adoptó por primera vez en 1900. Por último, estaría el modelo de gobierno por Consejo y Gerente. Éste es el modelo gerencialprofesional de gestión pública, en el que el Consejo municipal, elegido directamente por los ciudadanos, tiene la función de elaborar las normas y las políticas. Este Consejo que actúa como un Consejo de Administración, nombra un gerente, como único responsable ante él, de las funciones ejecutivas y administrativas, con absoluta autoridad sobre los directivos administrativos. También existe un Alcalde, que suele ser nombrado por el Consejo, pero sus funciones son estrictamente protocolarias. Este modelo fue adoptado por primera vez en 1908, y de él se predica la eficiencia administrativa, debida a la coordinación y dirección única, y por la capacidad, homologada y reconocida profesionalmente, del gerente. Este suele seleccionarse de entre miembros de la Asociación de city-managers (-gerentes locales-, que juegan un rol institucional de gran importancia, publicando incluso una Revista sobre estos temas, y actuando como un verdadero grupo de presión -lobby-). Las funciones que se le suelen asignar son las de plena autoridad para el nombramiento y cese de los responsables de los departamentos municipales; responsabilidad administrativa sobre el funcionamiento de los departamentos, con capacidad normativa en régimen interior; responsabilidad para la preparación y administración del Presupuesto municipal; responsabilidad directa para la formulación de la política administrativa horizontal o general; responsabilidad de la ejecución de los acuerdos del Consejo; responsabilidad en el cumplimiento de la legislación, en la actuación de la administración; asesorar y proponer actuaciones al Consejo sobre asuntos municipales, siendo asimismo miembro del Consejo y de todas las Comisiones con voz, pero sin voto.

«...como nos decía el jefe del departamento de presupuestos de la ciudad de Nueva York, "no hemos racionalizado la gestión en profundidad, hasta que no hemos tenido el agua de la crisis financiera al cuello". Es decir, la invención y experimentación exitosa de una nueva tecnología de gestión no supone su generalización, ya que normalmente será bloqueada por los intereses burocráticos, contrarios a su aplicación. 
EL GERENTE MUNICIPAL UNA APROXIMACIÓN AL CAMBIO ..

\begin{abstract}
Pero, cuando las constricciones financieras hacen inviables las estructuras y técnicas gestoras tradicionales, entonces se hace inevitable su reforma.» (Joan Prats, en Gobierno y Administración en las grandes ciudades).
\end{abstract}

Como síntesis de las diferentes experiencias a nivel comparado $y$, sin olvidar que se refieren a grandes ciudades (si bien que los males difieren en tamaño, pero no en características, respecto a las ciudades medianas y pequeñas), se podría decir que la gestión se canaliza a través de equipos gerenciales centrales, que además elaboran propuestas de planes y programas de alcance general, o de relieve para el conjunto de la actividad municipal, con el soporte de sistemas de información de gestión y los datos derivados del control de gestión. Pero, la combinación de equipos gerenciales con la tendencia a fortalecer los servicios centrales (que suelen incluir la gestión financiera, contable y de personal, los servicios jurídicos, de contratación y patrimonio, y los sistemas de información), comporta que lo que se centraliza es la elaboración de políticas y el soporte a la gestión, descentralizándose totalmente la gestión en sí, en los ámbitos sectoriales, tendiéndose cada vez más a prestarse los servicios, mediante fórmulas de Agencias o entes descentralizados. Lo que actúa como punto fuerte en estos modelos gerenciales es la comunicación entre los niveles políticos y de gestión, su implicación y alto grado de coordinación.

\title{
3.3. Modelos organizativos
}

Las Administraciones locales se caracterizan, respecto al resto de Administraciones, por no tener un modelo homogéneo organizacional. Los modelos difieren unos de otros, e incluso un mismo Ayuntamiento experimenta modelos distintos. Esta inquietud se debe a diversos motivos, entre ellos, el cambio de equipo de gobierno; las características del Alcalde, en una Administración en que la legislación la configura con un fuerte componente presidencialista; las modas en gestión; la presión social; la movilidad en los cuerpos de habilitación nacional, etc. Se podría decir que existen tres modelos-tipo, el de técnicos-administradores, el de dirección política y el gerencial, los cuales se dan en estado puro o con múltiples variedades, e incluso mezclándose. En este apartado haré una mención muy sintetizada de estos modelos, para pasar a explicar, si bien que esquemáticamente, los modelos gerenciales existentes en los Ayuntamientos de Barcelona y Esplugues de Llobregat.

\section{Modelo clásico con técnicos-administradores...}

Éste es un modelo formado, no por gestores, sino por técnicos-administradores, que en razón a su profesión o cuerpo asumen la dirección ejecutiva de su ámbito, bajo la dirección del Alcalde. 


\section{FIGURA 5. Modelo organizativo clásico de técnicos-administradores}

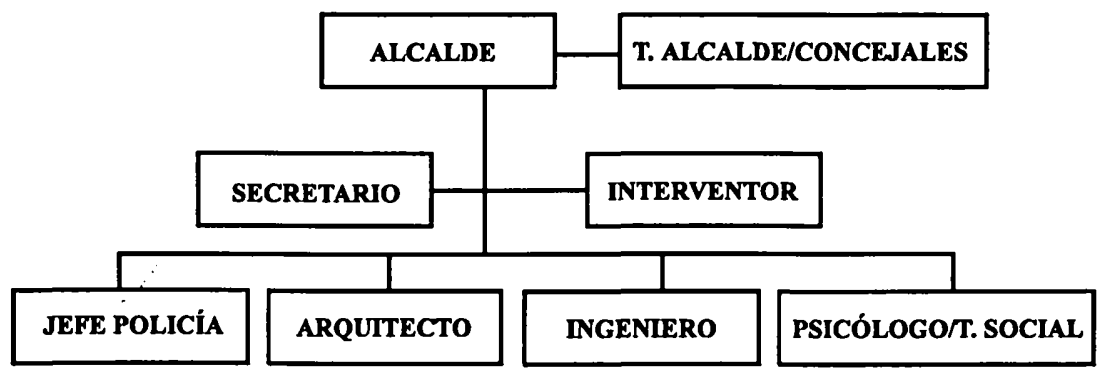

Elaboración propia.

\section{Modelo de dirección política...}

Es el más generalizado en la mayoría de Ayuntamientos, se caracteriza por la consideración del político como directivo, en base al sistema de delegaciones que realice el Alcalde. Es la otra manifestación de lo que no debería ser la gestión pública. En este modelo y, sin coherencia organizativa, sino de reparto de poder político, se estructura la organización, sin que exista una cohesión intraorganizativa, ni la participación y ejecución de las políticas públicas sobre la base de un proyecto común, lo cual se acentúa todavía más cuando existe un gobierno compuesto por más de una formación política. Los departamentos actúan como reinos de taifas, con autonomía propia y en tensión constante para hacer prevalecer sus propios fines a los de otros departamentos o el conjunto de la organización. La fuerza del departamento depende del poder que tenga el político ya sea en su partido o en la organización y se manifiesta en la dotación de recursos materiales y humanos, y la aprobación de las partidas presupuestarias que les corresponda. El personal del departamento tiene al frente un técnico, que actúa como asesor o ejecutor de las decisiones del político, pero no como un directivo, siendo el político el que decide sobre su actuación. Aquí se representa un diagrama tipo, que puede ser orientativo.

\section{Modelo gerencial (de directivos profesionales)...}

Este modelo se ha ido desarrollando progresivamente, esencialmente en municipios catalanes y valencianos. En él, se tiende, como es común en los modelos gerenciales de los municipios occidentales, sobre los cuales ya se hizo referencia, a diferenciar el nivel político del nivel directivo en la gestión públi- 


\section{FIGURA 6. Modelo organizativo de dirección política}

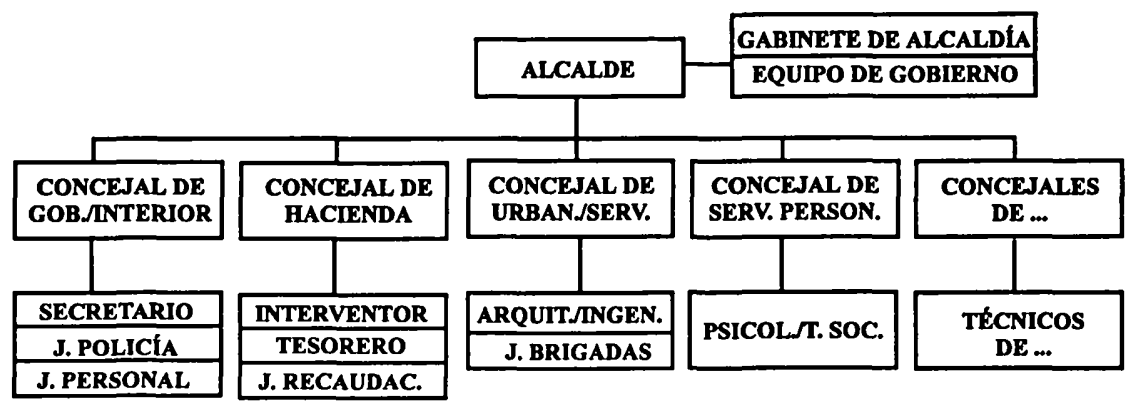

Elaboración propia.

ca. El nivel político se dedica a la definición y traslación de políticas públicas a los ciudadanos, con una presencia constante en instituciones, entidades y en la propia sociedad de su municipio, compartiendo esta tarea con sus actividades profesionales propias. El nivel directivo se dedica a una participación activa en la definición de las políticas públicas, y a su ejecución, al mismo tiempo que lleva a cabo la dirección ejecutiva de la organización. Se basa en la figura del Gerente y/o Directores/Coordinadores de Áreas funcionales, territoriales (en este caso cuando se constituyen organizaciones propias territoriales descentralizadas, como los distritos) e instrumentales (cuando existen entes instrumentales mediante personificaciones jurídico-públicas, como organismos autónomos - patronatos o agencias...-, o jurídico-privadas, como empresas públicas o mixtas...), sobre una compartimentalización racional y orientada a la gestión, de la Administración municipal. Dichas figuras se proveen con profesionales especializados en la dirección, gestión, control e implementación organizacional, y se debe tender a su formación permanente, ajustándose al perfil de directivo explicado en el apartado correspondiente.

«En el ámbito local no se puede plantear una estrategia o un sistema de gestión a partir de lo que se recoja en los manuales, ya que el camino a recorrer está lleno de obstáculos. Cada Ayuntamiento debe adaptar la gestión a sus necesidades, pero necesita de un gerente, porque el mercado lo reclama» (Josep MARULL, 1997).

Voluntariamente, no he hecho figurar ni al Pleno, ni a la Comisión de Gobierno, ni a las Comisiones informativas, ni a los órganos colegiados de los entes instrumentales. Ya que, aunque es el Pleno el que aprueba el diseño organizativo al aprobar la relación de puestos de trabajo y plantillas, así como el nombra- 


\section{FIGURA 7. Modelo organizativo gerencial}

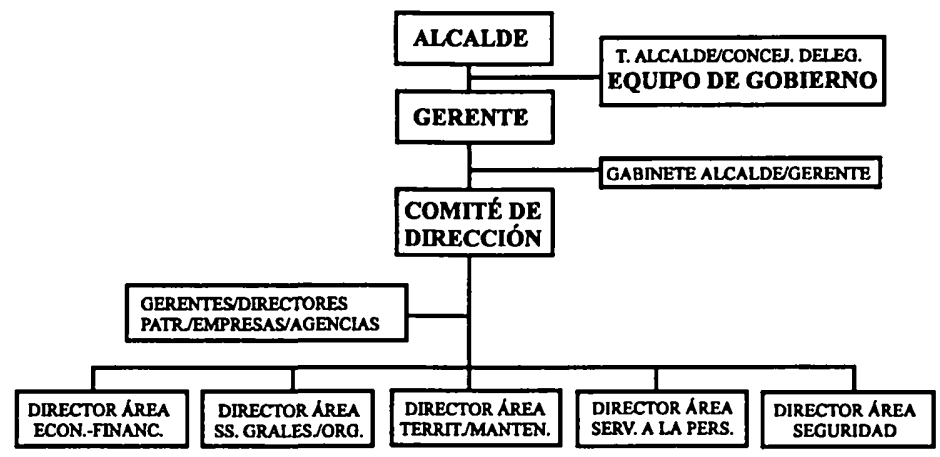

Elaboración propia.

miento del personal directivo, y las Comisiones informativas los debaten $\mathrm{e}$ informan preceptivamente, e incluso, si así se le ha delegado, la Comisión de Gobierno asume importantes competencias en materia organizativa y de personal, aparte de órgano asesor del Alcalde, la realidad es que son el Equipo de gobierno (formado por todos los concejales o por los más representativos) y, en primera instancia el Alcalde, los que con el correspondiente juego de las mayorías, definen el modelo de organización que gobiernan, e inciden, directamente, sobre el modelo de gestión que desean. Y, para su implantación, es esencial el liderazgo claro del Alcalde. Mientras que para su consolidación es necesaria la implicación de todos los grupos políticos con representación municipal, lo cual suele ser difícil. Será la articulación normativa municipal, así como el transcurso del tiempo y la capacitación de los directivos, los inputs importantes para la aceptación del modelo gerencial, independientemente de que comporte el cambio de las personas.

Estos modelos, no me ha parecido oportuno explicarlos desde los conceptos de estructuración de las organizaciones de H. MiNTZBERG (qué es vértice estratégico, línea media, núcleo de operaciones, staff y tecnoestructura), porque la realidad local, no es tan simple, ya que quien debería estar en la tecnoestructura (como el Secretario o Interventor), muchas veces es en realidad vértice estratégico, y en éste, las decisiones muchas veces se conforman con incidencia del núcleo de operaciones (sindicatos, personal de base...) o desde agentes externos a la organización (partidos políticos, entidades...). La teoría de política de gestión de MinTZBERG, no es fácilmente aplicable a las organizaciones que constituyen la Administración local. En sentido similar se ha manifestado BLOK (El manager fortalecido. Paidós), que considera que no existe la autoridad ab- 
soluta en una organización, como propugna MINTZBERG, por lo que hay que adoptar políticas que den sentido a la organización, procurando que los empleados adopten conductas basadas en la responsabilidad y la autonomía.

\section{Dos experiencias singulares...}

...son las que ahora se apuntan, si bien que cual ameba, la función gerencial en la gestión pública, se va extendiendo poco a poco. El primer Ayuntamiento que la implantó, allá en los albores de la recuperación democrática, fue el de Sant Boi de Llobregat (Barcelona), con Josep M. ${ }^{a}$ Procházka como gerente, como se enorgullece de recordar. Pero como variantes del modelo gerencial, son los correspondientes al de Barcelona y al de Esplugues de Llobregat (Barcelona), los que aquí haré mención.

En Barcelona, y sobre la base jurídica de la Ley especial de 1960, se instituyó en el anterior mandato electoral el modelo gerencial, siendo su primer gerente Francisco Longo, y el posterior y actual Josep Marull, pero se podría decir que se ha apostado por un modelo, en el que no existe uno, sino varios gerentes, según una distribución funcional y territorial, concibiéndose la figura del gerente de servicios generales como un primus inter pares, que en la realidad actúa como gerente de gerentes, con funciones de impulso y coordinación sobre los demás, en el marco del Comité ejecutivo, como órgano colegiado creado para la dirección superior de la administración ejecutiva. Siendo un político, el 1. ${ }^{\text {er }}$ Teniente de Alcalde, por delegación del Alcalde, el que preside y dirige dicho Comité, actuando de vertebrador entre el nivel político y directivo. Los gerentes o directivos de los entes instrumentales se adscriben organizativamente en el sector funcional o territorial correspondiente, coordinándose con el gerente del mismo. Corresponde a los órganos de gobierno, compuestos por miembros corporativos, la aprobación de las políticas a las que ajustarán su actuación los gerentes. Por otro lado, los miembros electos con responsabilidades de gobierno coordinan la ejecución de las políticas, pudiendo realizar tareas de control, pero su relación no se da sobre la dirección jerárquica, sino sobre la coordinación-información. A la comisión ejecutiva se le atribuyen las funciones de coordinación de la actuación de los diferentes sectores de actuación, de establecimiento de criterios generales de gestión, y de preparación e informe de los asuntos que se sometan a deliberación por los órganos colegiados de gobierno. La regulación y funciones de esta figura, se contempla en un corpus administrativo aprobado y modificado por Decretos de Alcaldía (puesto que se parte de una interpretación forzada de la Ley del 60, que atribuía al Alcalde el nombramiento de los Delegados de servicios), sobre «normas básicas para la ordenación de los ámbitos en la administración municipal ejecutiva». Entre las delegaciones efectuadas, se les ha atribuido la capacidad de dictar actos admi- 
nistrativos. Bajo este primer nivel gerencial se establece un segundo nivel directivo, en el que se incluyen los Directores de servicios y responsables de entes instrumentales, como responsables máximos de los correspondientes entes, departamentos o áreas administrativas en que se estructura cada sector funcional y territorial. Todos ellos son nombrados por libre designación.

En Esplugues de Llobregat, como municipio mediano, se ha implantado un modelo gerencial más puro. Se crea por acuerdo plenario, en el cual también se nombra, por libre designación, a quien ha de ocupar el cargo, Enric Giner, atribuyéndosele las funciones correspondientes, con una gran coherencia para que la consolidación del modelo sea exitosa. Entre dichas funciones, debería destacarse una que es significativa de la separación entre los niveles político y directivo. Es la que le atribuye la elaboración y formulación de programas anuales y plurianuales de inversión en que se concreten los planes de actuación y que constituirían el contenido de los capítulos de inversión de los presupuestos municipales. En el mundo local el presupuesto de inversiones es el de mayor importancia estratégica y política, ya que a través de él se materializa el futuro de ciudad, sus infraestructuras y equipamientos. Atribuir esta facultad al gerente, es creer en una gestión pública profesional, en la que el directivo participa activamente en la definición de las políticas y se encarga de su ejecución y evaluación. Es importante apreciar cómo los requisitos que se establecen para cubrir el puesto son los de «conocimientos, formación y experiencia probada en funciones de dirección y coordinación». El modelo es muy similar al que se ha dibujado en la figura 7, dependiendo toda la organización ejecutiva del gerente (el cual está auxiliado de adjuntos), que depende del Alcalde, el cual pasa a asumir un rol más representativo, difusor externo de las políticas y vertebrador entre el nivel político y la organización, en la definición de esas políticas. En este modelo se ha integrado a los cuerpos nacionales en el comité de dirección, que preside el gerente implicándolos en la organización como personal directivo, lo cual se reconoce como un éxito para la implantación del modelo.

«El gerente ha de ser una persona que cohesione la estructura administrativa, con liderazgo, siendo consciente de que actúa en el campo de las relaciones humanas, pudiéndose adaptar a los cambios a los que debe anticiparse, siendo previsor. Debe actuar con paciencia, la cual es amarga pero otorga frutos dulces. Ante todo debe ser un profesional con capacidad suficiente para canalizar las sinergias entre el nivel político y la organización, debiendo saber aportar elementos de decisión al primero, con lo que debe tener abiertos muchos canales de información, que también le permitan disponer de los máximos elementos para su actuación. Para ello debe contar con capacidad de análisis crítico y experimentar constantemente, modificando y ajustando en cada momento para conseguir de la organización sus mejores resultados» (Enric Giner, gerente del Ayuntamiento de Esplugues. Febrero de 1997). 


\subsection{El marco jurídico en Cataluña}

\section{La legislación vigente...}

...sobre la organización en la Administración municipal, se compone de la Ley 8/1987, de 15 de abril, municipal y del régimen local de Cataluña, el Decreto-Legislativo 1/1997, de 31 de octubre, por el que se aprueba el texto refundido de los preceptos de determinados textos legales vigentes en Cataluña, en materia de función pública, el Decreto 214/1990, de 30 de julio, que aprueba el reglamento de personal de los entes locales y, su modificación por adaptación a la Ley 30/1992, de 26 de noviembre, de Régimen jurídico de la Administración pública y del procedimiento administrativo común, el Decreto 179/1995, de 13 de junio, por el que se aprueba el Reglamento de obras, actividades y servicios de los entes locales (ROAS), ambos de la Generalitat de Cataluña, el RD 2568/1986, de 28 de noviembre, del Estado, que aprueba el Reglamento de organización, funcionamiento y régimen jurídico de las entidades locales, el Reglamento Orgánico municipal, cuando aborde este tema y los documentos acompañatorios del Presupuesto correspondientes a la relación de puestos de trabajo y plantilla. Normativa vigente en el marco de la legislación básica contenida en la Ley 7/1985, de 2 de abril, de bases del régimen local, y el RD Legislativo 781/1986, de 18 de abril, que aprueba el texto refundido de las disposiciones legales vigentes en materia de régimen local.

En este marco hay que diferenciar la organización ejecutiva del Ayuntamiento de la organización ejecutiva de sus entes instrumentales.

\section{Desde la organización ejecutiva del Ayuntamiento}

Como se puede apreciar, el marco jurídico vigente permite nombrar Gerentes en el nivel directivo máximo de la organización local, al mismo tiempo que permitir la existencia de personal propio en ese nivel. En todo caso debe recogerse en la relación de puestos de trabajo, con las correspondientes consignaciones presupuestarias. En muchas ocasiones se consideran los puestos de nivel técnico como de nivel directivo, lo cual es un error, y, aunque es posible, no responde al diseño efectuado por la normativa y referenciado anteriormente. Ello ocurre, porque la rigidez o precariedad funcionarial del personal eventual, así como la tendenciosa identificación política por los partidos que se encuentren en la oposición, hace huir de una aplicación coherente de la normativa, tanto por el personal, como por los políticos que asuman el gobierno. 
FIGURA 8. Marco jurídico del nivel directivo y superiores en la organización ejecutiva

\begin{tabular}{|c|c|c|c|c|}
\hline & Ambito & Cuerpo & Provisión & $\begin{array}{c}\text { Organo } \\
\text { que nombra }\end{array}$ \\
\hline NIVEL DIRECTIVO & $\begin{array}{l}\text { Área o servicios complejos } \\
\text { Área o servicios ordinarios } \\
\text { Área o serv. especializados }\end{array}$ & $\begin{array}{l}\text { Personal eventual } \\
\text { T. Admón. Gral. } \\
\text { T. Admón. Especial }\end{array}$ & $\begin{array}{l}\text { Libre designación } \\
\text { Concurso/Libre des. } \\
\text { idem. }\end{array}$ & $\begin{array}{l}\text { Pleno } \\
\text { Pleno } \\
\text { idem. }\end{array}$ \\
\hline NIVEL TECNICO & $\begin{array}{l}\text { Servicios consultivos y de } \\
\text { control } \\
\text { Servicios especializados }\end{array}$ & $\begin{array}{l}\text { Cuerpos Nacionales } \\
\text { T. Admón Especial }\end{array}$ & $\begin{array}{l}\text { Concurso/Libre des. } \\
\text { Acc. Directo de selec. }\end{array}$ & $\begin{array}{l}\text { Pleno/MAP } \\
\text { Estado }\end{array}$ \\
\hline \multirow{2}{*}{ NIVEL GESTOR } & \multirow{2}{*}{$\begin{array}{l}\text { Servicios páblicos } \\
\text { sectoriales }\end{array}$} & Administrador & Concurso & Pleno \\
\hline & & \multicolumn{3}{|c|}{$\begin{array}{l}\text { - Esta figura aparece como novedad en el art. } 191.2 \text { del } \\
\text { ROAS, como gestor de! servicio, sin posibilidad de ejer- } \\
\text { cer funciones resolutorias, ni disponer gastos. No se re- } \\
\text { gula su provisión, ni pertenencia, por lo que se entiende } \\
\text { que son puestos de trabajo que pueden ser ocupados por } \\
\text { personal municipal, mediante las normas generales de } \\
\text { provisión de puestos. }\end{array}$} \\
\hline
\end{tabular}

Elaboración propia.

Desde la organización ejecutiva de los entes instrumentales de gestión directa

FIGURA 9. Marco jurídico de la organización ejecutiva en los entes instrumentales

\begin{tabular}{|lll|}
\multicolumn{1}{c|}{ ENTE } & \multicolumn{1}{c|}{ CARGO } & $\begin{array}{l}\text { ORGANO } \\
\text { que nombra }\end{array}$ \\
\hline NIVEL DIRECTIVO & $\begin{array}{l}\text { Organización especial ............. Gerente } \\
\text { Organismo autónomo............ } \\
\text { Sociedad mercantil pública.......... Gerente }\end{array}$ & $\begin{array}{l}\text { Aleno } \\
\text { Junta general }\end{array}$ \\
\hline
\end{tabular}

Elaboración propia.

Como se aprecia, en los modelos de gestión directa regulados por el ROAS, y anteriormente, por el Reglamento de servicios de 17 de junio de 1955, se exige la existencia de un gerente. El caso de la organización especial es relevante, puesto que se encuentra en la propia estructura orgánica del Ayuntamiento, no teniendo personalidad jurídica propia. En todos los casos, el gerente se configura legalmente como un órgano de gobierno, al que se atribuye la dirección y gestión inmediata, y el puesto no puede ser ocupado por un miembro electo. 


\subsection{Mucho más que una figura o un modelo}

Como se ha expuesto no existe ningún inconveniente para la implantación de la figura. Pero lo importante es el modelo de gestión. Un modelo que crea en la existencia de personal directivo que asuma la función gerencial en la organización y que separe el nivel político del directivo. Ello se ha recogido como experiencia en Cataluña, en la organización de los Consejos comarcales, que, quizás bajo la influencia de las mancomunidades, han confiado en la figura del gerente que se ha creado como un órgano administrativo, con competencias asignadas por la Ley, y con un carácter esencialmente profesional (así se puede comprobar en la Ley 6/1987, de organización comarcal de Cataluña). Ello es lógico, puesto que al estar cubiertos los otros órganos de gobierno (Presidencia y Pleno), por miembros electos de Ayuntamientos, sobre los que se entiende que no pueden tener la dedicación necesaria en la Comarca, se optó por agilizar la acción administrativa con un órgano estable, en cuanto a la presencia del que lo ocupara, el cual tiene atribuida la dirección de la administración y servicios comarcales. El problema ha aparecido con la asunción de competencias por estos entes, desde la Generalitat y desde los Ayuntamientos, por delegación. A partir de ahí, se ha tendido a primar en quien ocupa este órgano, más su ascendencia y actuación política, que no profesional, de acuerdo con las políticas que apruebe el Pleno a través de los planes comarcales.

Por otro lado, es de agradecer y valorar positivamente el proyecto de reglamento de organización, funcionamiento y régimen jurídico (ROF), del Departamento de Gobernación de la Generalitat (siempre y cuando algún día vea la luz), que en su segundo borrador y, dentro del Título 1 sobre la organización de los entes locales, prevé en la sección $6 .^{\mathrm{a}}$ del Capítulo 1, sobre estructura de la organización, la figura del gerente, al cual se le atribuye la dirección ejecutiva de los servicios técnico-administrativos centrales, y se reenvía al Reglamento orgánico de la Corporación, para que se articule el estatuto de sus funciones. Éste es un avance enorme, pero la figura no servirá para nada si detrás no existe un modelo de gestión, que asuma el Ayuntamiento como su política pública organizacional. Esta figura no puede existir sola, ya que debería hablarse de personal directivo, como hace la ley municipal y el reglamento de personal. Lo que queda claro es que no responde a la figura del gerente comarcal. Por otro lado, no se tiene en cuenta la posibilidad de que, a través del Reglamento orgánico o de Ordenanzas fiscales, se pueda desconcentrar en ellos la competencia para dictar actos de gestión, de acuerdo con las pautas que da el art. 11 de la Ley 30/1992, para la creación de unidades y órganos administrativos y con la definición como acto repetitivo o de aplicación mecánica del procedimiento, contra el que cabe recurso ordinario, que da la Ley General Tributaria. En todo caso deberían realizarse las reformas legislativas correspondientes para que, si así se considera por la Corporación, también pueda asumir facultades delega- 
das. Asimismo, no es comprensible, cuando existen antecedentes en nuestra propia tradición local (como en Barcelona con los Delegados de servicios), que el máximo o máximos directivos del Ayuntamiento no puedan formar parte de los órganos colegiados de gobierno, al menos con voz, cuando luego será el responsable de la ejecución de los acuerdos que allí se adopten, ya que lo que se prevé en el proyecto de ROF es, que en todo caso, asista como asesor y cuando se le requiera. Es necesario un cambio cultural importante, para el cual se requiere un debate político sobre los modelos de gestión en nuestra Administración local.

Se ha explicado entre las causas originarias de la aparición de la figura en el ámbito local español, la orientación a la eficiencia, la falta de especialización en la gestión y de dedicación de los políticos, el incrementalismo de servicios a partir de la recuperación democrática, el nivel competencial asumido por los municipios, el alcance del techo presupuestario y fiscal, el aumento y capacitación de los recursos humanos y la complejidad prestacional por la diversidad de servicios, como las más características. Pero en este apartado también hay que señalar la limitación del Alcalde de no poder formar su gobierno, cosa que no ocurre en el resto de Administraciones. En la Universidad, en el Estado, en las Autonomías, el Presidente y Rector (en la Universidad, a la cual también se le reconoce autonomía con garantía institucional en su aspecto organizativo, y que reconoce como órgano necesario la figura del gerente, con competencias muy importantes en el funcionamiento de la organización), electos, eligen su equipo de gobierno y sus directivos (aunque no estén conceptuados con las características que aquí se defienden para serlo), pero ello no ocurre en el nivel local. El Alcalde forma su equipo de gobierno y compone la Comisión de gobierno con y entre Concejales electos, de acuerdo con las candidaturas aprobadas por los correspondientes partidos o agrupaciones electorales. Ello también ha sido causa, para que tras estos años se busque, en los directivos profesionales que designa, implantar una dirección profesional de la Administración, reconduciendo el papel de los miembros electos a la definición de objetivos, políticas y programas, su difusión en la sociedad, su control y defensa ante los órganos colegiados, y a la implicación en Instituciones y sociedad impulsando el nuevo enfoque relacional de la actuación administrativa.

La consideración de los entes locales como instancias políticas de representación popular, como Administraciones públicas esencialmente prestacionales, no nos puede llevar a un enfoque economicista de su gestión, cual si de una empresa se tratara. Se ha de poder combinar el modelo de gestión pública de la burocracia weberiana con el modelo gerencial en un marco relacional y en un entorno cambiante. Ya se ha incidido exhaustivamente en este carácter diferenciador. Lo que necesita la Administración local son directivos que permitan conseguir la rentabilidad social de los servicios, la satisfacción de los ciuda- 
EL GERENTE MUNICIPAL. UNA APROXIMACIÓN AL CAMBIO ...

danos/usuarios/clientes, la implicación del personal, el diseño y ejecución de políticas públicas que aporten un beneficio a la sociedad, la racionalización de los recursos organizativos y económico-financieros, el cumplimiento y respeto de la legalidad y la igualdad y no discriminación, la protección de los valores sociales. Que orienten a la Administración en la adaptabilidad a los cambios sociales. Que sean emprendedores, en una sociedad interrelacional, facilitando la participación de los diferentes agentes tanto en el diseño y ejecución de políticas, como en la prestación de servicios. Que respondan de su actuación ante la organización y los órganos de gobierno. Que entienda la Administración desde una perspectiva global que permita su cohesión.

«No hay viento favorable para aquél que no sabe a dónde va». (SÉNECA en Cartas a Lucilio).

\section{El cubo de Rubik, paradigma de la gestión local}

«Ésta sería la esencia del enfoque de la eficacia social: su orientación clara hacia un proyecto de futuro (de ciudad) y la participación técnica, social y ciudadana».

Antonio Diaz. Municipio relacional: la eficacia social. Madrid, 1993.

Cuando se popularizó el cubo mágico, inventado por el profesor húngaro Ernö Rubik para sus alumnos de arquitectura, a principios de los 80, para facilitarles la comprensión de los problemas de forma y espacio, era fácil ver grupos de personas que intentaban realizar las combinaciones suficientes, con la destreza necesaria para conseguir que el cubo tuviera todos los lados homogéneos, si bien que de un color diferente cada uno. La dificultad era tal, que todos intentaban manipular el cubo a la vez, requiriéndose la ayuda entre ellos, pero sólo uno pudiendo manipularlo. Se requería concentración y atención para que el intento no acabara en frustración y, ante todo implicaba la interrelación. Lo mismo ocurre en la Administración local, la interrelación entre todos los agentes existentes en su entorno no sólo es necesaria, sino que no se puede obviar. Y ello comporta que no se pueda ver la gestión aislada y su aplicación como prácticas de laboratorio. La gestión interactúa en un marco de políticas públicas, las cuales se configuran en un entorno político muy definido, en el que los partidos adquieren un predominio excluyente, pero interactivo con otros agentes sociales, y desde su carácter representativo y a través del correspondiente proceso electoral se legitiman en la asunción del gobierno. La gestión se relaciona con las políticas públicas, pero ya no con la política, en la que no incide y con la que sí interactúan los agentes sociales. Con estas interdependencias, aumenta la complejidad, de lo que podríamos denominar la gobernabilidad, que atraviesa una crisis a nivel internacional, a raíz de la globalización de los mercados, que ha generado dinamismo e interdependencia y seguirá generando 
mayor complejidad y entornos diversos. A través de los procedimientos políticos, de las reglas del juego político democrático, se concilian intereses contrapuestos, en constante búsqueda de equilibrio y negociación, con el objetivo de integrar racionalidades diferentes y conjugar los valores sociales en un constante presente.

Y, como ya se explicó en el apartado correspondiente, la eficiencia de las organizaciones no sólo depende de factores internos, sino también externos, como el marco institucional en el que se mueve y la generación de confianza y cultura ciudadana en los diferentes agentes, teniendo en cuenta su capital social e implicándoles en el propio sentido de la organización, evitando una patrimonialización política o burocrática, mediante una personalización del interés general. El papel de las organizaciones públicas no sólo debe ser receptor, sino también difusor. No sólo hay que gestionar bien, sino explicar que los servicios tienen unos costes, que lo que han costado es razonable y de dónde proviene ese dinero. Culturizando así el entorno social y permitiéndole la implicación en los objetivos de la organización.

Nuestro entorno social, se caracteriza por un envejecimiento de la población, un mantenimiento de los altos niveles de paro y una precarización laboral que incide más directamente sobre los jóvenes y las mujeres, con el consecuente empobrecimiento de las familias. Por otro lado, nos encontramos en el techo de la presión fiscal y de los niveles de endeudamiento y déficit, que comporta un reequilibrio presupuestario. Ante ello la Administración tiene el reto de incidir directamente sobre la cohesión social y el mantenimiento y calidad de servicio a los ciudadanos y de sus infraestructuras, tiene el reto de ser una Administración emprendedora y configurar una gestión pública relacional. $Y$ este reto sólo lo puede afrontar, si desde el nivel político se definen los modelos de gestión necesarios para la consecución del modelo de ciudad, de Estado y como conjunción, de sociedad, que los ciudadanos refrendarán.

«El cambio organizativo depende muy especialmente del liderazgo organizacional. Ello involucra, en las Administraciones Públicas, no sólo a la cultura administrativa sino también y fundamentalmente a la propia cultura política. Desde la concepción gerencial de las Administraciones Públicas se refuerza la vieja verdad de que el cambio no es posible sin voluntad y compromiso político. ¿Para cuándo?» (Joan Prats. Formación, modelos organizativos y perfiles gerenciales en las Administraciones Públicas. Barcelona, 1989).

\section{REFERENCIAS SOBRE ORGANIZACIÓN}

a) El art. 3.4 de la Ley 30/1992, de 26 de noviembre, de Régimen Jurídico de las Administraciones Públicas y Procedimiento Administrativo Común (Ley 30/92) 
EL GERENTE MUNICIPAL UNA APROXIMACIÓN AL CAMBIO .

prevé que cada una de las Administraciones públicas actúa para el cumplimiento de sus fines con personalidad jurídica única.

b) Son varios los artículos de la CE que se refieren a los poderes públicos, en un concepto globalizador que incluye tanto los órganos constitucionales del Estado, como las personas jurídico-públicas (como ejemplo arts. 9, 27, y 39 a 51 , entre otros).

c) Ley 30/1992, de 26 de noviembre, que en su art. 2 dice: «1. Se entiende a los efectos de esta Ley por Administraciones Públicas: a) La Administración General del Estado. b) Las Administraciones de las Comunidades Autónomas. c) Las Entidades que integran la Administración local. 2. Las Entidades de Derecho Público con personalidad jurídica propia vinculadas o dependientes de cualquiera de las Administraciones Públicas tendrán asimismo la consideración de Administración Pública.»

d) Del Tribunal Supremo son representativas las Sentencias de 6 de junio de 1990 -RA 4814 - de 12 de junio de 1987 - RA 6120_, de 24 de diciembre de 1990 - RA 10191 - de 20 de octubre de 1992 -RA 8036- Del Tribunal Constitucional, la 178/1989, de 2 de noviembre, la 143/1991, de 1 de julio, la 192/1991, de 14 de octubre, la 200/1991, de 28 de octubre y la 238/1992, de 17 de diciembre, entre otras. Sentencias sobre el principio de eficacia.

e) Es interesante la posición doctrinal de algunos administrativistas sobre el principio de eficacia. Así, se pronuncia Luis ORTEGA en «El reto dogmático del principio de eficacia» en $R A P, \mathrm{n} .^{\circ} 133$, pág. 11 , cuando dice que «muchos derechos constitucionales precisan para su plenitud del concurso de la Administración... no basta con resultado de garantía jurídica, sino que son fundamentales los resultados de servicio, porque es en la medición del resultado donde se puede concretar el contenido del derecho de prestación. Resultado que en muchos casos lo podrá concretar el legislador en base a estándares medios de cantidad, calidad o temporalidad». En esa línea incide también Ramón MARTín MATEO en «El sistema administrativo clásico y su permeabilidad a los nuevos paradigmas» en Revista de Administración Pública (RAP), n. 134 , pág. 22.

f) Luciano Parejo en Eficacia y Administración (obra citada), pág. 95 y ss., realiza un conciso análisis de la evolución del concepto desde el punto de vista de la organización y, en relación a la eficiencia, desde las posiciones de ET-

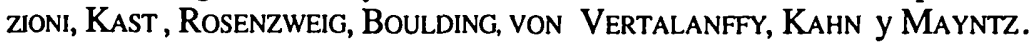


REALA 274-275 (MAYO-DICIEMBRE, 1997)

g) El art. 3.2 de la Ley de Régimen Jurídico de las Administraciones Públicas... prevé que «Las Administraciones públicas... se rigen... en su actuación por los criterios de eficiencia y servicio a los ciudadanos».

\section{BIBLIOGRAFÍA CONSULTADA}

M. Artola Gallego y M. Pérez Ledesma, Historia del mundo contemporáneo. Edita Anaya, 1988.

E. BarRachina Juan, «El recurso por desviación de poder». Cuadernos $j u$ rídicos, 5 .

F. J. BarRanco, «La nueva gestión de recursos humanos». Capital Humano, $\mathrm{n}^{\text {os }}$ 24-25-26-28, 1990.

J. M. Belaza Vázques y J. A. García Revilla, Gestión de recursos humanos y organización interna. Edita BCL, 1993.

M. BELTRÁn, La productividad de la Administración española: Un análisis comparativo. Edita Ministerio de Economía y Hacienda, 1991.

J. M. BENITEZ DE LUGo, El municipio y sus elementos esenciales. Edita el autor, 1986.

P. Block, El manager fortalecido. Edita Paidós, 1990.

C. Bolx , «Hacia una Administración Pública eficaz: Modelo institucional y cultura profesional en la prestación de servicios públicos» $(G A P P), \mathrm{n} .^{\circ} 1,1994$.

S. CASESSE, «Dirigenza pubblica in Italia». Regione e Governo locale, $\mathrm{n},{ }^{\circ}$ 4, 1990.

J. Castelao Rodríguez, Manual de organización y funcionamiento de las entidades locales. MAP, 1990.

R. CAStro AlCaide, «Los Consells comarcals. Un estudio de caso. La comarca del Baix Llobregat». Revista de Estudios de la Administración Local y Autonómica (REALA), n. ${ }^{\circ} 248,1990$.

J. CHIAS, Marketing público. Por un Gobierno y una Administración al servicio del público. McGraw Hill, 1995.

A. CHOY, «La funció pública dels ens locals a Catalunya». Ponencia presentada al seminario organizado por la EAPC sobre función pública territorial europea, 1992. 
EL GERENTE MUNICIPAL UNA APROXIMACIÓN AL CAMBIO ...

Documento. L'organització política i administrativa de l'Ajuntament de Barcelona. Documento elaborado por el Ayuntamiento de Barcelona, como Memoria explicativa de su organización municipal, 1997.

P. Dunleavy y C. Hood, «De la Administración Pública tradicional a la nueva gestión pública. Ensayo sobre la experiencia modernizadora de diversos países desarrollados», (GAPP), n. ${ }^{\circ} 3,1995$.

J. M. ECHARRI, «La prospectiva estratégica: una herramienta básica para la gestión empresarial». Harvard-Deusto Business Review, n. $75,1996$.

K. Echebarría Ariznabarreta, «La función gerencial en las Administraciones públicas. Particularidades de la gestión pública». Temas de gerencia pública, tema 56, (FGAP), ESADE, 1996.

K. Echebarría Ariznabarreta, «La función gerencial en las Administraciones Públicas». Apuntes FGAP, ESADE, 1996.

K. Echebarría Ariznabarreta, «Los procesos de modernización de las Administraciones públicas en Europa». Comunicación del programa FGAP, ESADE, 1996.

K. Echebarría Ariznabarreta, «La paradoja de la reforma administrativa de las Comunidades Autónomas». Papers ESADE, n. ${ }^{\circ}$ 135, 1995.

K. Echebarría Ariznabarreta, «El cambio y la gestión del cambio en la Administración Pública». En la obra colectiva Modernización administrativa. Edita Instituto Vasco de Administración Pública, 1989.

P. Fabregat Romero y C. Uranga Cogollos, «La selección de personal en la Administración Pública: El mito del Administrador educado». Revista Internacional de Ciencias Administrativas, vol. 57, n. ${ }^{\circ} 2,1991$.

T. R. FERNÁNDEZ, «De nuevo sobre el poder discrecional y su ejercicio arbitrario». Revista española de Derecho Administrativo (REDA), 1993.

G. Franchi Scarselli, «Funzioni pubbliche territoriali (il modelo italiano)». Ponencia presentada en el seminario organizado por la Escuela de Administración Pública de Cataluña (EAPC), sobre Función pública territorial europea, 1992.

A. GoRE, «Crear una función pública que funcione mejor y cueste menos. De los trámites burocráticos a los resultados». Informe del National Perfomance Review. Edita Instituto Vasco de Administración Pública, 1994.

A. Guillén ZaNón, «La técnica del grupo nominal». $D A, \mathrm{n}^{\circ} 223,1990$.

A. Guillén Zanón y E. R. NúÑEZ de PRAdo, «Administración por objetivos». $D A, \mathrm{n}^{\circ} 223,1990$. 
REALA 274-275 (MAYO-DICIEMBRE. 1997)

INFORME OCDE. La Administración al servicio del Público. MAP, 1991.

R. Jiménez AsEnSio, «La dirección de la Administración Pública como función del gobierno». Revista Vasca de Administración Pública, n. ${ }^{\circ} 34,1992$.

M. JIMÉNEZ DE PARGA, La ilusión política. ¿Hay que reinventar la democracia en España? Alianza editorial, 1993.

D. F. KETTL, «Más allá de la retórica de la reinvención: Una reflexión sobre las reformas Clinton de la gestión pública», $(G A P P)$, n. ${ }^{\circ} 1,1994$.

C. Kosniovski, Domine fácilmente el cubo mágico. Editorial Fontalba, 1981.

J. P. KotTER, «Lo que hacen realmente los buenos directores generales». Harward-Deusto Business Review, 1983.

F. Longo, «Políticos, Directivos y Sindicatos como actores de la gestión de recursos humanos en las Administraciones Públicas». Papers ESADE, n. ${ }^{\circ} 148$, 1996.

J. López Camps y A. Gadea Carrera, El control de gestión en la Administración local. Edita Fund, Emi books, 1992.

C. LosADA, «Competencias requeridas para los puestos directivos en la Administración Federal de los EE.UU.». Comunicación programa FGAP, ESADE, 1996.

C. LoSADA, «La naturaleza del trabajo directivo». Apuntes FGAP de ESA$D E, 1996$.

A. Manuel Abellán, «Los representantes y el derecho de participación en el ordenamiento jurídico español». Revista de Estudios Políticos, n. ${ }^{\circ}$ 84, 1994.

MAPCAL, S.A., El plan de negocios. Díaz de Santos, 1994.

L. MARCONI, «Un'ipotesi di efficienza e di efficacia nella pubblica amministrazione». Revista trimestrali di Scienza dell'Amminstrazione, n. ${ }^{\circ} 2,1991$.

J. MarchenA, «El método Delphi». (DA), n. ${ }^{\circ} 223,1990$.

R. Martín Mateo, «El sistema administrativo clásico y su permeabilidad a los nuevos paradigmas de la calidad total». $R A P, \mathrm{n} .^{\circ} 134,1994$.

J. Mas y C. Ramıó, Tècniques d'auditoria operativa aplicades a l'Administració Pública. Edita Departament de Governació, Generalitat de Catalunya, 1992.

J. Mauri Majós, «Direcció i gestió pública». Apuntes del Curso sobre gestión de recursos humanos en la Administración local de la EAPC, 1992. 
EL GERENTE MUNICIPAL UNA APROXIMACIÓN AL CAMBIO ...

X. Mendoza Mayordomo, «Las transformaciones del sector público en las democracias avanzadas: del Estado del bienestar al Estado relacional». Ponencia del Seminario organizado por la UIMP. La sanidad: un sector en cambio, 1995.

X. Mendoza Mayordomo, «Técnicas gerenciales y modernización de la Administración pública en España». DA, n. ${ }^{\circ} 223,1990$.

X. Mendoza Mayordomo, «El escenario de la competitividad y sus implicaciones para las Administraciones Públicas en los años 90». Comunicación programa FGAP, ESADE, 1996. 1989.

L. MeTCALFE y S. RichaRdS, La modernización de la gestión pública. MAP,

B. MEUNIER, La gerencia de las organizaciones no comerciales. MAP, 1993.

H. MinTzBerg, La estructuración de las organizaciones. Ariel, 1990.

H. MintzBeRG, «Las tareas de la dirección: Mito y realidad». Harvard Business Review, 1975. Traducción J. L. Samaranch, ESADE, 1992.

M. T. Mogín, «La modernización de la Administración pública». Ponencia del seminario sobre función pública territorial europea, 1992.

M. H. Moore, La creación de valor en el sector público. Edita J. F. Kennedy School of Government. Traducción M. C. García-Sicilia, ESADE, 1984.

L. Morell Ocaña, El régimen local español. Civitas, 1988.

L. Morell Ocaña, El sistema de la confianza política en la Administración Pública. Civitas, 1994.

A. NiETo, La organización del desgobierno. Ariel, 1990.

L. ORTEGA, «EI reto dogmático del principio de eficacia». $R A P, \mathrm{n} .^{\circ} 133,1994$.

V. Ortún Rubio, «Gestió Pública». Revista Económica de Catalunya, 1992.

D. Osborne y T. Gaebler, La reinvención del gobierno. Paidós, 1994.

L. Parejo Alfonso, Eficacia y Administración. Tres estudios. Instituto Nacional de Administración Pública, Boletín Oficial del Estado, 1995.

J. R. PASTOR MiLÁN, «Els gerents a l'Administració local: anàlisi d'una jove experiència». Papers de formació municipal, Diputación de Barcelona, n. ํ 6, 1994.

B. G. Peters, «La moral en la función pública». Revista Internacional de Ciencias Administrativas, vol. 57, n. ${ }^{\circ} 3,1991$. 
C. K. Prahalad y G. Hamel, «La estrategia como objetivo de estudio ¿por qué buscar un nuevo paradigma?». Harvard-Deusto Business Review, n. ${ }^{\circ}$ 75, 1996.

J. Prats Català, «Política, gestión y administración de recursos humanos en las Administraciones Públicas». Documentación Administrativa (DA), $\mathrm{n}^{\text {os }} 210$ $211,1987$.

J. Prats Catala, «La gobernabilidad democrática y crisis de gobernabilidad de sociedades actuales». Apuntes no publicados del Curso de Función gerencial de Administraciones Públicas (FGAP) de ESADE, 1996.

J. Prats CatalA, «Formación, modelos organizativos y perfiles gerenciales en las Administraciones Públicas». En VV.AA. La formación para la Administración local en los 90. Ayuntamiento de Barcelona, 1989.

J. Prats Català, Derecho y management en las Administraciones Públicas. Notas sobre la crisis y renovación de los respectivos paradigmas. Instituto de Dirección y Gestión Pública, ESADE, 1993.

R. QuirogA, «Poder y política». Comunicación del programa FGAP, ESADE, 1996.

J. E. Ricart y J. L. Álvarez, Cómo prepararse para las organizaciones del futuro. Folio-IESE, 1996.

Sue RichaRDS, «El paradigma del cliente en la gestión pública». Revista de Gestión y Análisis de Políticas Públicas (GAPP), n. ${ }^{\circ}$ 1, 1994. 1996.

X. Sala Martín, «Massa govern». Barcelona management review, n. 3,

J. Subirats, Análisis de políticas públicas y eficacia de la Administración. MAP, 1989.

J. SubiRATs, «La acción política en la Administración local». En obra colectiva Ponencias del Seminario de Derecho local. Ayuntamiento de Barcelona, 1992.

J. VALERO, «EI trabajo en equipo», $D A, \mathrm{n}^{\circ} 223,1990$.

C. Valls Cerulla, «La gestión de personal en la Administración local». Ponencia presentada en el seminario organizado por el Colegi de Secretari i Interventors de Barcelona, 1996.

VV.AA., Manual de Govern Local. Federación de Municipios de Cataluña, 1995.

VV.AA., Nueva gestión local. Editorial Popular, 1993. 
EL GERENTE MUNICIPAL UNA APROXIMACIÓN AL CAMBIO ...

VV.AA., Algunas experiencias de organización y gestión de recursos humanos. Banco de Crédito Local (BCL), 1993.

VV.AA., «Govern i Administració a les grans ciutats». (Documents de treball per a la Carta municipal) I. Ayuntamiento de Barcelona, 1987. 
